\title{
小分子给体/高分子受体型有机太阳能电池研究进展
}

\author{
苗俊辉 丁自成刘俊* 王利祥 \\ (中国科学院长春应用化学研究所 高分子物理与化学国家重点实验室 长春 130022)
}

\begin{abstract}
摘要 有机太阳能电池具有低成本、柔性和质量轻等优势, 是一种有应用前景的光伏技术, 受到人们的广泛关注. 有机 太阳能电池的光敏活性层通常由 $\mathrm{p}$-型有机半导体(包括小分子和高分子)与 $\mathrm{n}$-型有机半导体(包括小分子和高分子)共混 而成. 小分子给体/高分子受体型有机太阳能电池具有形貌热稳定性优异的特点, 值得深入研究. 本综述旨在总结小分 子给体/高分子受体型有机太阳能电池的研究进展，分别介绍了基于酰亚胺基、氰基和含硼氮配位键( $\mathrm{B} \leftarrow \mathrm{N})$ 的高分子受 体的活性层材料体系的发展状况. 在器件性能方面, 通过分子设计、相分离形貌调控, 改善了小分子给体/高分子受体 的匹配性, 将该类电池的能量转换效率从最初的 $0.29 \%$ 提升至目前的 $9.51 \%$, 为性能的进一步提升总结了经验; 在稳定 性方面, 基于该体系形貌热稳定性优异的特点, 开发出高温耐受型有机太阳能电池器件. 最后, 展望了小分子给体/高 分子受体型有机太阳能电池的未来发展方向和前景.
\end{abstract}

关键词＼cjkstart有机太阳能电池；小分子给体；高分子受体；相分离形貌；热稳定性

\section{Research Progress in Organic Solar Cells Based on Small Molecule Donors and Polymer Acceptors}

\author{
Junhui Miao Zicheng Ding Jun Liu* Lixiang Wang \\ (State Key Laboratory of Polymer Physics and Chemistry, Changchun Institute of Applied Chemistry, \\ Chinese Academy of Sciences, Changchun 130022, China)
}

\begin{abstract}
Due to their advantages of low cost, flexibility and light weight, organic solar cells (OSCs) are considered to be a promising photovoltaic technology for practical applications and have received great attentions. The active layers of OSCs are the blends of conjugated small molecule/polymer electron donors and electron acceptors. Before 2013, the most-widely used electron acceptors are fullerene derivatives. Nevertheless, the weak absorption in the visible region, limited electronic tunability, and poor morphological stability hinder their further application in OSCs. Non-fullerene electron acceptors with good light harvesting ability and tunable energy levels have developed rapidly in past few years. Based on the types of electron donor and acceptor materials, non-fullerene OSCs may be classified into four types, including polymer donor/polymer acceptor blend $\left(\mathrm{P}_{\mathrm{D}} / \mathrm{P}_{\mathrm{A}}\right)$, polymer donor/small molecule acceptor blend $\left(\mathrm{P}_{\mathrm{D}} / \mathrm{M}_{\mathrm{A}}\right)$, small molecule donor/polymer acceptor blend $\left(\mathrm{MD}_{\mathrm{D}} / \mathrm{P}_{\mathrm{A}}\right)$, and small molecule donor/small molecule acceptor blend $\left(\mathrm{MD}_{\mathrm{D}} / \mathrm{M}_{\mathrm{A}}\right)$. Among various kinds of OSCs, $\mathrm{M}_{\mathrm{D}} / \mathrm{P}_{\mathrm{A}}$-type OSCs possess the excellent morphology stability under thermal stress, which is worthy of further study. Although the advantages of $\mathrm{M}_{\mathrm{D}} / \mathrm{P}_{\mathrm{A}}$-type OSCs, there are still large challenges in their development. The power conversion efficiencies (PCEs) of $\mathrm{M}_{\mathrm{D}} / \mathrm{P}_{\mathrm{A}}$-type OSCs are still much lower than that of other type OSCs, due to the limited material combination of small molecule donors and polymer acceptors and undesirable phase separation morphology of the active layers. In this review, we summarize the research progress of OSCs based on small molecule donors and polymer acceptors, and introduce the active layer material systems from three type polymer acceptors, i.e. the imide group, cyano group and boron-nitrogen coordination bond $(\mathrm{B} \leftarrow \mathrm{N})$ unit based polymer acceptors. Benefiting from the development of both donor and acceptor materials as well as the manipulation of phase-separation morphology in active layers, the good match between small molecule donors and polymer acceptors is achieved. This not only boosts the large improvement in PCE from $0.29 \%$ to $9.51 \%$, but also contributes to a high-temperature tolerant photovoltaic device. Finally, we also present an outlook of the future development of high-performance $\mathrm{M}_{\mathrm{D}} / \mathrm{P}_{\mathrm{A}}$-type OSCs.
\end{abstract}

Keywords organic solar cell; small molecule donor; polymer acceptor; phase-separation morphology; thermal stability

\section{1 引言}

有机太阳能电池因其柔性、质量轻, 可低成本溶液 加工、大面积组装等特点, 有望在便携式、可穿戴能源
技术中得到应用，近年来受到广泛关注 ${ }^{[1-4]}$. 有机太阳能 电池是将具有光敏性质的有机物作为活性层夹在阴极 与阳极之间, 通过光生伏特效应产生电压, 形成电流,

*E-mail: liujun@ciac.ac.cn

Received December 30, 2020; published February 23, 2021.

Project supported by the National Natural Science Foundation of China (Nos. 21625403, 51873204) and the National Key Research and Development Program of China (No. 2019YFA0705900) funded by Ministry of Science and Technology (MOST).

项目受国家自然科学基金(Nos. 21625403, 51873204)和科技部国家重点研究发展项目(No. 2019YFA0705900)资助. 
从而实现光能向电能的转化 ${ }^{[5-6]}$. 作为一种新能源技术, 有机太阳能电池有望成为硅基等无机太阳能电池的有 效补充, 实际应用前景广阔. 而面向实际应用, 需要协 同考虑有机太阳能电池的效率、成本和稳定性 ${ }^{[7-9]}$.

有机太阳能电池的活性层通常是由 $\mathrm{p}$-型的电子给 体材料和 $\mathrm{n}$-型的电子受体材料共混的体异质结结构, 而 有机小分子或高分子都可作为电子给体或电子受体材 料 ${ }^{[10-18]}$. 按照体异质结有机太阳能电池活性层中电子受 体的种类差异, 可分为富勒烯型有机太阳能电池和非富 勒烯型有机太阳能电池. 基于富勒烯受体的有机太阳能 电池是由富勒烯及其衍生物 ${ }^{[19]}$, 如 $[6,6]$-苯基- $\mathrm{C}_{61}$-丁酸 甲酯 $\left(\mathrm{PC}_{61} \mathrm{BM}\right),[6,6]$ - 苯基- $\mathrm{C}_{71}$-丁酸甲酯 $\left(\mathrm{PC}_{71} \mathrm{BM}\right)$ 和狮 双加成富勒烯衍生物(ICBA) 等作为受体, 具有空穴传输 性质的小分子或高分子作为给体. 在有机太阳能电池最 初发展的 20 年里, 由于富勒烯衍生物高的电子亲和势、 优异的电荷传输性质以及与给体共混易于调控的相分 离形貌, 基于富勒烯受体的有机太阳能电池得到了广泛 的研究, 实现了超过 $11 \%$ 的能量转换效率(PCE) ${ }^{[20-23]}$. 但是, 富勒烯类受体具有一些固有的缺点, 如能级不可 调节, 在可见和近红外光区吸光能力弱, 形貌稳定性较 差等, 极大限制了该类体系的进一步发展. 为了克服这 些缺点, 基于非富勒烯受体的有机太阳能电池应运而 生. 相比富勒烯类受体材料, 非富勒烯受体材料具有化 学结构易修饰, 能级、光谱可调节, 形貌较稳定等优点. 基于以上优势, 近年来基于非富勒烯的有机太阳能电池 成为有机光伏领域的研究热点, 发展迅速 ${ }^{[24-26]}$. 目前, 非富勒烯型有机太阳能电池取得了极大的进展, 器件效 率已经突破 $17 \% 0^{[13-15,27-35]}$.

根据活性层中给体与受体的种类差异(小分子或高 分子), 非富勒烯有机太阳能电池又可分为以下四类: 高分子给体/小分子受体型、全高分子型、全小分子型和 小分子给体/高分子受体型. 其中, 性能最为突出的是基 于高分子给体和小分子受体共混的有机太阳能电池. 占 肖卫等 ${ }^{[36]}$ 开发出以稠环单元为中心核, 强拉电子单元 为端基的 A-D-A 型小分子受体材料 ITIC, 该分子具有 强的吸光能力、合适的能级和优异的电荷传输性质, 与 高分子给体共混后展示出高的器件性能. 鉴于该分子的 巨大潜力, 在全世界掀起了稠环电子受体材料发展的热 潮. 在众多课题组的参与下, 对此类 A-D-A 型稠环电子 受体材料进行模块化分子设计, 开发出众多性能优异的 小分子受体材料, 如 IDIC、IT-4F 以及 $\mathrm{CO}_{i} 8 \mathrm{DFIC}$ 等 ${ }^{[37-43]}$, 使高分子给体/小分子受体型有机太阳能电池实现超过 $13 \%$ 的效率. 而最近, 邹应萍等又发展了另一类基于 A-D-A-D-A 构型 ${ }^{[25,44-45]}$ 的高效稠环电子受体材料, 如 Y6, 目前基于此类稠环小分子受体可以实现超过 $17 \%$ 的器件效率. 此外, 在小分子稠环电子受体材料的带动 下, 全小分子型 ${ }^{[46-56]}$ 和全高分子型 ${ }^{[57-61]}$ 有机太阳能电池 在近几年也取得了极大的进展, 器件性能也得到明显提
升, 目前基于这两个体系都实现了超过 $15 \%$ 的器件性 能.

小分子给体/高分子受体型有机太阳能电池是由小 分子给体材料和高分子受体材料共混构成其活性层(图 1). 相比其他类型的有机太阳能电池，小分子给体/高分 子受体型有机太阳能电池的发展相对滞后, 器件性能相 对较低, 目前最高 PCE 为 $9.5 \%$. 但在多个体系中发现小 分子给体/高分子受体型有机太阳能电池通常具有优异 的形貌稳定性，特别是在高温条件下，仍能保持良好的 形貌, 维持较高的器件性能 ${ }^{[62-67]}$. 考虑到有机太阳能电 池面向实际应用的稳定性要求, 形貌稳定性优异的小分 子给体/高分子受体型有机太阳能电池值得深入研究. 自 2014 年, 占肖卫等 ${ }^{[68]}$ 以小分子 $p$-DTS(FBTTh $\left.{ }_{2}\right)_{2}$ (图 3) 为给体, 以菲二酰亚胺(PDI)类高分子 PPDIDTT(图 2)为 受体初次报道了一组小分子给体/高分子受体型有机太 阳能电池材料体系, 实现了 $0.29 \%$ 的器件性能. 随后研 究者们基于以 PDI 或萗二酰亚胺(NDI)单元的高分子受 体、含氰基的高分子受体以及含嗍氮配位键 $(B \leftarrow N)$ 的高 分子受体，通过给受体材料的匹配，共混相分离形貌的 优化，逐步提升该体系的效率，目前已经实现超过 $9 \%$ 的能量转换效率，而且仍然有很大的提升空间.

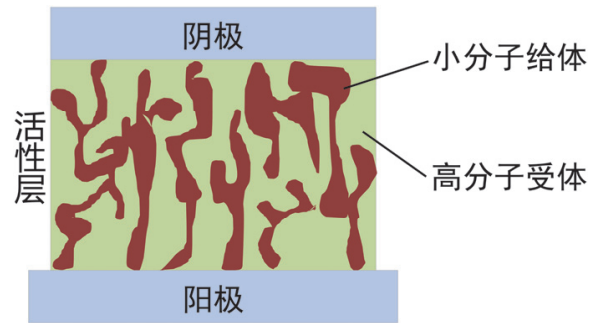

图 1 小分子给体/高分子受体型有机太阳能电池的器件结构示意图 Figure 1 Schematic diagram of the device structure of organic solar cell based on small molecule donor and polymer acceptor

本综述旨在总结目前小分子给体/高分子受体型有 机太阳能电池体系取得的一系列研究进展. 以小分子给 体/高分子受体型有机太阳能电池中的高分子受体材料 体系为主线，如酰亚胺基高分子受体、氭基高分子受体 和含 $\mathrm{B} \leftarrow \mathrm{N}$ 类高分子受体，分别从分子设计、相分离形 貌调控角度介绍了小分子给体/高分子受体体系的材料 发展和器件性能优化, 另外介绍了有关器件稳定性方面 的研究. 最后, 展望小分子给体/高分子受体型有机太阳 能电池的未来发展方向和前景.

\section{2 小分子给体/高分子受体型有机太阳能电池 的发展}

\section{1 基于酰亚胺基高分子受体的小分子给体/高分子受 体型有机太阳能电池}

\section{1 .1 含酰亚胺基团的高分子受体}

高分子受体材料要求具有低的最低未占据分子轨 
道(LUMO)/最高已占据分子轨道(HOMO) 能级, 因此有 强缺电子性质的酰亚胺结构经常会被用于高分子受体 材料的分子设计中, 例如芢二酰亚胺(PDI)和荎二酰亚 胺(NDI)单元 ${ }^{[69-78]}$. 由于 PDI 单元和 NDI 单元有较大的 $\pi$-共轭平面和强的拉电子能力, 基于 PDI 单元或 NDI 单 元的高分子受体通常具有优异的电子传输性质和强的 电子亲和能力.

2.1.2 $p$-DTS( $\left(\mathrm{FBTTh}_{2}\right)_{2}$ 小分子给体/酰亚胺基高分子受 体有机太阳能电池

在 2014 年, 占肖卫等 $[68]$ 通过高分子/小分子的给体 材料和受体材料相互匹配的方式首次报道了一组小分 子给体/高分子受体型有机太阳能电池. 作者选择 PDI 单元与二噻吩并噻吩 (DTT) 单元的交替共聚物 PPDIDTT(图 2)作为受体, 选择 D-A-D-A-D 构型的小分 子 $p$-DTS $\left(\mathrm{FBTTh}_{2}\right)_{2}$ (图 3) 作为给体. 由于小分子 $p$-DTS(FBTTh $\left.{ }_{2}\right)_{2}$ 高的结晶性质和强的聚集能力, 与高 分子 PPDIDTT 共混后, 形成断裂的、非连续的小分子 结晶相, 导致大尺寸的相分离形貌, 影响激子向给/受体 $(\mathrm{D} / \mathrm{A})$ 界面的扩散和解离. 另外, 小分子给体过强的结 晶性抑制了高分子受体的传输, 致使共混膜中的电子迁 移率较低, 仅为 $2.4 \times 10^{-7} \mathrm{~cm}^{2} \cdot \mathrm{V}^{-1} \cdot \mathrm{s}^{-1}$, 导致电荷传输 不平衡. 结果基于该体系仅实现了 $0.29 \%$ 的器件性能.
随后，为了解决高结晶性的小分子给体在与高分子 受体共混时易结晶导致大尺寸相分离的问题，作者基于 相同的高分子受体 PPDIDTT，选择具有较小尺寸的方 酸类小分子 DIB-SQ(图 3)作为给体，并制备双层结构的
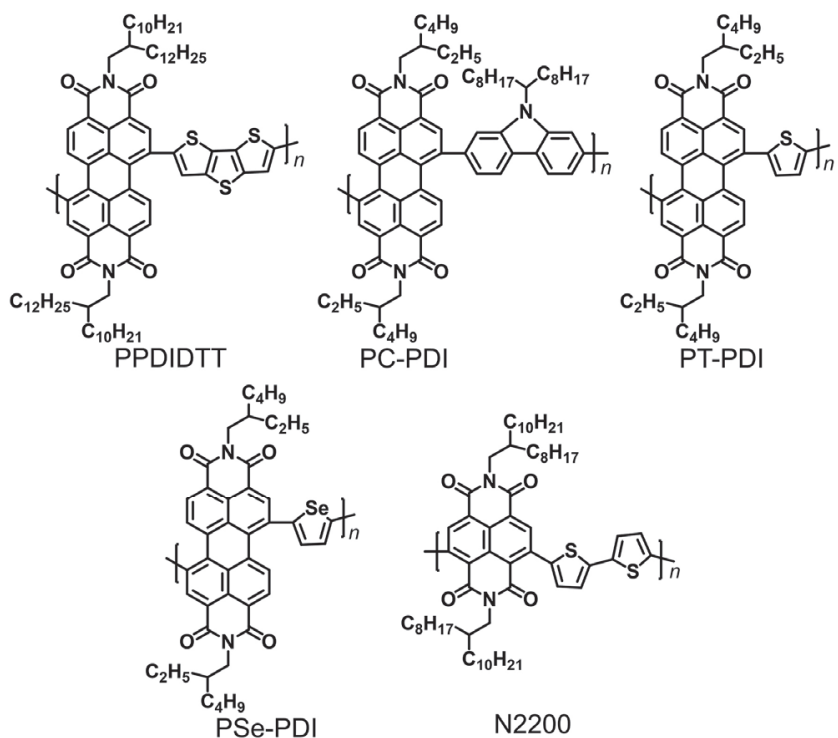

图 2 用于小分子给体/高分子受体型有机太阳能电池的酰亚胺基高 分子受体的化学结构

Figure 2 Chemical structures of imide-based polymer acceptors for $\mathrm{M}_{\mathrm{D}} / \mathrm{P}_{\mathrm{A}}$-type OSCs
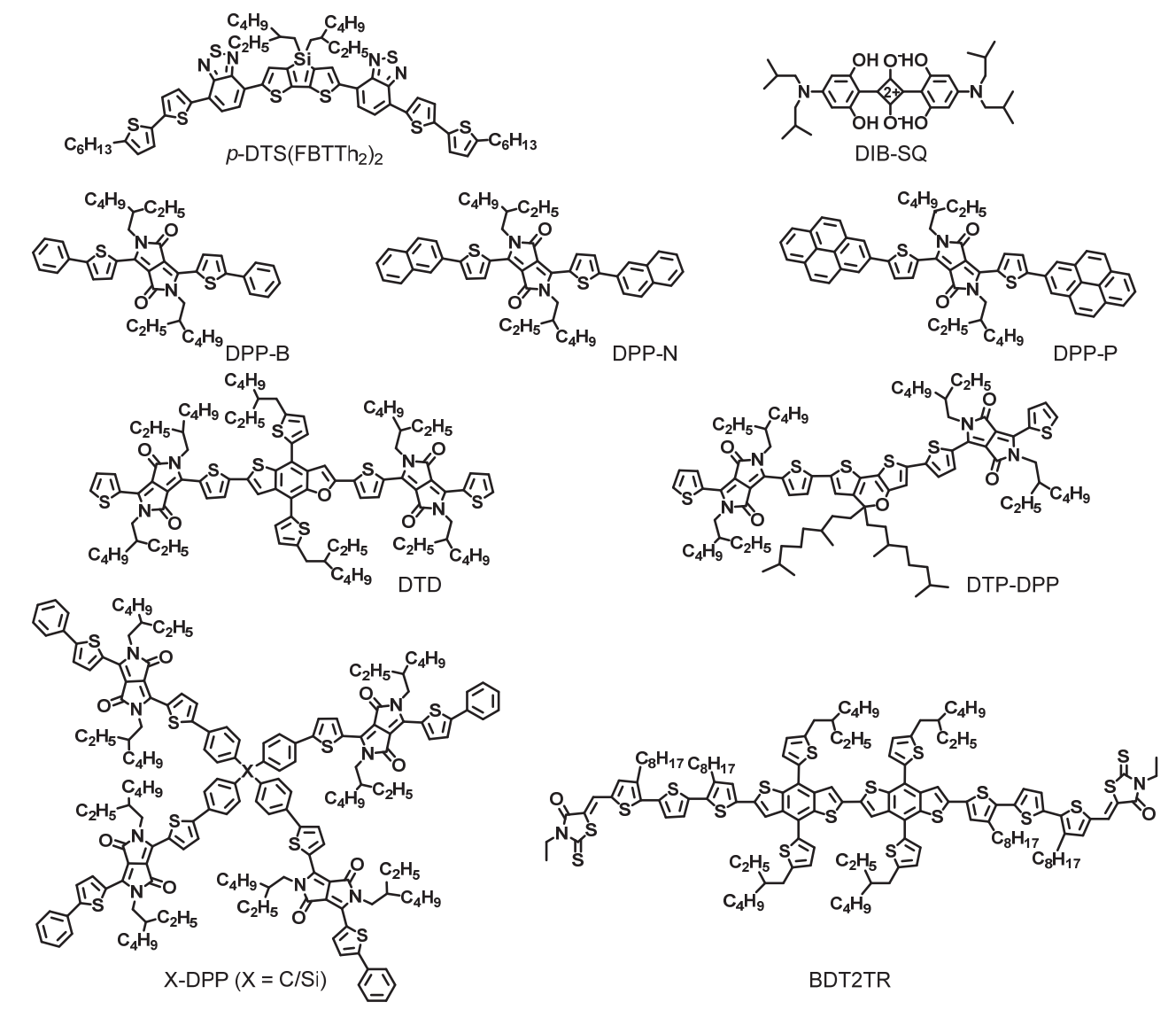

BDT2TR

图 3 用于小分子给体/高分子受体型有机太阳能电池的小分子给体的化学结构

Figure 3 Chemical structures of small molecule donors for $\mathrm{M}_{\mathrm{D}} / \mathrm{P}_{\mathrm{A}}$-type OSCs 
小分子给体/高分子受体型有机太阳能电池 ${ }^{[79]}$. 随后通 过热退火的手段促进小分子 DIB-SQ 的热运动, 使其部 分扩散到高分子受体中, 形成给受体的共混相. 与直接 共混的体异质结结构相比, 双层结构的活性层有效地缓 解了因小分子过度结晶导致的相区尺寸大的问题, 实现 了 $1.12 \%$ 的器件性能.

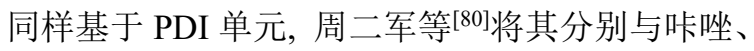
噻吩、硒酚等单元共聚开发出一系列高分子受体材料 PC-PDI、PT-PDI 和 PSe-PDI(图 2). 作者选择小分子 $p$-DTS $\left(\mathrm{FBTTh}_{2}\right)_{2}$ 为给体与这些 PDI 类高分子受体匹配 构筑小分子给体/高分子受体型有机太阳能电池材料. 通过二维掠入射广角 $\mathrm{X}$ 射线衍射(2D-GIWAXS)探究了 共混膜的相分离形貌, 结果发现, 当给受体分别共混后, 在共混薄膜中主要出现强度较弱的小分子 $p$-DTS $\left(\mathrm{FBTTh}_{2}\right)_{2}$ 的特征衍射信号, 说明在成膜过程中 由 $p$-DTS $\left(\mathrm{FBTTh}_{2}\right)_{2}$ 的结晶主导相分离形貌, 但高分子 受体会扰乱小分子的结晶. 随后, 通过添加剂 1,8 -二碘 辛烷(DIO)的加入, 延长成膜时间, 使小分子结晶性增 强, 形成连续相, 从而改善空穴传输. 其中, 基于 PSe-PDI: $p$-DTS(FBTTh $\left.{ }_{2}\right)_{2}$ 的活性层体系获得 3.01\% 的器 件性能.

除 PDI 类高分子受体外, NDI 类高分子受体也被用 于小分子给体/高分子受体型有机太阳能电池体系. 在 NDI 类高分子受体中, 基于 NDI 单元与联噻吩单元的交 替共聚物 N2200(图 2) 是应用最为广泛, 研究最为深入

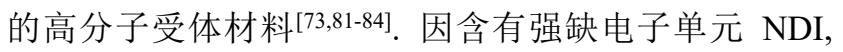
$\mathrm{N} 2200$ 具有低的 LUMO 能级, 达到 $-4.0 \mathrm{eV}$, 使其可以 和大多给体材料匹配. N2200 有两个吸收带, 且光学带 隙仅为 $1.44 \mathrm{eV}$, 光谱覆盖从可见光区至近红外区, 可以 保证足够的光吸收. 另外, N2200 因良好的骨架平面性, 展示出优异的电子传输能力, 如在有机场效应晶体管中 可以实现 $0.85 \mathrm{~cm}^{2} \cdot \mathrm{V}^{-1} \cdot \mathrm{s}^{-1}$ 的电子迁移率. 因 $\mathrm{N} 2200$ 低 的 LUMO 能级, 窄带隙的吸收光谱和高的电子迁移率, 作为受体用于有机太阳能电池, 可以实现了超过 $12 \%$ 的 器件性能.

基于高分子受体 N2200 低能级、窄带隙和高电子迁 移率的特点, 早在 2014 年, Nguyen 等 ${ }^{[85]}$ 将其与小分子 给体 $p$-DTS $\left(\text { FBTTh }_{2}\right)_{2}$ 共混制备了有机太阳能电池器件. 作者首先通过提高共混溶液的旋涂温度制备有序性较 差的共混薄膜, 随后通过 $80{ }^{\circ} \mathrm{C}$ 热退火处理或加入少量 的 DIO 提高给受体的有序性(图 4), 改善薄膜的结晶性, 提高电荷传输能力, 最终将 $p$-DTS $\left(\mathrm{FBTTh}_{2}\right)_{2}: \mathrm{N} 2200$ 体 系的器件性能从 $0.61 \%$ 提升至 $2.11 \%$. 在同样的体系中, Park 等 ${ }^{[62]}$ 详细研究了不同热退火 $\left(80\right.$ 至 $\left.200{ }^{\circ} \mathrm{C}\right)$ 对活性 层形貌和器件性能的影响. 在一定温度范围内的热退火 处理可以有效提高共混薄膜的结晶性, 改善电荷传输, 其中在 $180{ }^{\circ} \mathrm{C}$ 热退火条件下实现了 $3.02 \%$ 的器件性能. 值得注意的是, $p$-DTS(FBTTh $\left.{ }_{2}\right)_{2}: \mathrm{N} 2200$ 共混薄膜展示出
高的热稳定性, 在 $180{ }^{\circ} \mathrm{C}$ 条件下热处理 $20 \mathrm{~h}$ 仍能维持 原性能的 $70 \%$. 通过原子力显微镜(AFM)测试发现, 其 共混形貌经过高温热处理 $\left(180{ }^{\circ} \mathrm{C}, 20 \mathrm{~h}\right)$ 几乎没有发生 大的改变, 展示出极高的形貌稳定性, 因此该体系的活 性层具有良好的热稳定性. 该结果说明小分子给体/高 分子受体型有机太阳能电池体系在高温稳定器件方面 具有潜力.

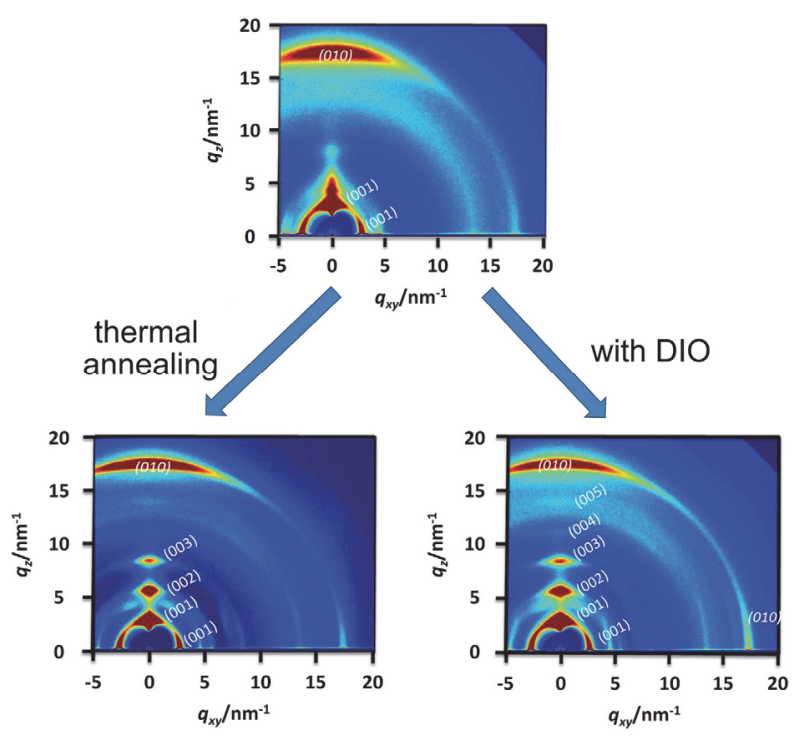

图 4 基于 $p$-DTS( $\left.\mathrm{FBTTh}_{2}\right)_{2}: \mathrm{N} 2200$ 共混薄膜经过热退火或加入 DIO 处理的 2D-GIWAXS ${ }^{[85]}$. 版权 2014, WILEY-VCH.

Figure 4 2D-GIWAXS patterns of $p$-DTS(FBTTh $\left.)_{2}\right)_{2} \mathrm{~N} 2200$ blend films at thermal annealing or with $\mathrm{DIO}^{[85]}$. Copyright 2014, WILEY-VCH.

在以上小分子给体/高分子受体型有机太阳能电池 材料体系中, 小分子给体大多采用 $p$-DTS $\left(\mathrm{FBTTh}_{2}\right)_{2}$, 虽 然该分子具有强的光吸收能力和高的空穴传输性质, 但 是其强的聚集性质和结晶能力致使在成膜过程中主导 共混形貌, 容易形成大尺寸的相分离, 导致低的器件性 能.

2.1 .3 含吡咯并吡咯二酮(DPP)单元的小分子给体/酰亚 胺基高分子受体有机太阳能电池

研究者们开发出其他类型的小分子给体材料, 如吡 咯并吡咯二酮(DPP)类和苯并二噻吩(BDT)类, 用于小 分子给体/高分子受体体系. DPP 单元是含有两个内酰胺 基团的对称稠环结构, 常作为缺电子单元被用于电子给 体材料的设计中 ${ }^{[86-87]}$. 马万里等 ${ }^{[88]}$ 以 DPP 单元为中心 核, 噻吩为 $\pi$ 桥, 分别以苯环、菜环和萠环作为末端基 团设计合成一系列结晶性不同的小分子给体, DPP-B、 DPP-N 和 DPP-P(图 3). 结果发现, 随末端基团从苯环、 萗环到萠环, 小分子的骨架平面性得到改善, 固态堆积 更加有序, 结晶性提高, 电荷迁移率提升. 作者用高分 子 N2200 作为受体, 与之共混制备活性层, 并通过溶剂 添加剂 DIO 和热退火处理调节其结晶尺寸. 其中以萠环 为末端基团的小分子 DPP-P 体系因高的空穴传输能力, 获得最优的能量转换效率, 为 $2.05 \%$. DPP 单元也被作 
为末端基团用于小分子给体的设计中, 如 Inganäs 等 ${ }^{[89]}$ 使用噻吩并苯并呋喃(TBF)为中心核, 噻吩连接的 DPP 单元(ThDPP)为末端基团设计合成小分子 $\mathrm{DTD}$ (图 3). 该分子的吸收光谱主要覆盖范围为 $500 \sim 750 \mathrm{~nm}$, 宽的 吸收光谱保证了足够的光吸收; 较低的 HOMO 能级使 其与 N2200 受体之间有小的 HOMO 能级差, 使其获得 小的能量损失; 此外由于良好的骨架平面性, 该分子具 有高的空穴迁移率. 作者用高分子 N2200 作为受体, 与 DTD 共混制备活性层, 并通过溶剂添加剂氯萘 $(\mathrm{CN})$ 减 小 N2200 的聚集尺寸, 获得小尺寸的相分离形貌, 从而 获得较高的短路电流 $\left(J_{\mathrm{SC}}\right)$ 和填充因子 $(\mathrm{FF})$, 实现 $3.74 \%$ 的器件性能. Jo 等 ${ }^{[90]}$ 则以二噻吩并吡喃(dithienopyran) 为中心核, ThDPP 为末端基团得到小分子 DTP-DPP(图 3 ). 由于强的分子内电荷转移(ICT)作用, DTP-DPP 具有 窄的光学带隙, 仅为 $1.52 \mathrm{eV}$, 吸收光谱覆盖从 500 至 $800 \mathrm{~nm}$. 此外, 通过差示扫描量热(DSC)测试, DTP-DPP 展示出明显的熔融峰和结晶峰; 通过 GIWAXS 测试, 其 在面外可以观察到明显的多级衍射信号, 表明该分子在 固态下具有强的结晶性. 将 DTP-DPP 作为给体与高分 子受体 N2200 共混, 通过溶剂添加剂 CN 调节活性层形 貌, 实现了 $4.82 \%$ 的器件性能. Jen 等 ${ }^{[91]}$ 分别以四苯基甲 烷和四苯基硅烷为中心核, 外围连接 ThDPP, 以苯为端 基设计合成两个三维结构的小分子给体 C-DPP 和 Si-DPP(图 3). 由于四苯基甲烷和四苯基硅烷中的碳原 子和硅原子都采取 $\mathrm{sp}^{3}$ 杂化, 因此外围连接的 ThDPP 单 元可以像 “臂” 一样向外伸展, 从而抑制分子在固态下 的堆积. DSC 结果显示两个分子都没有明显的熔融结晶 峰, 说明分子的结晶性较差. 将这两个无定型的小分子 给体与半晶性的高分子受体 N2200 共混, 可以形成纳米 尺寸的相分离形貌, 分别实现 $4.64 \%$ 和 $4.02 \%$ 的器件性 能. 相比 Si-DPP:N2200 体系, C-DPP:N2200 体系更优的 器件性能与其平衡的电子/空穴传输有关.

2.1 .4 含 $\mathrm{BDT}$ 单元的小分子给体/酰亚胺基高分子受体 有机太阳能电池

BDT 单元因具有较大的共轭平面, 良好的对称性 和优异的电荷传输性质被广泛应用于小分子给体材料 的设计中 ${ }^{[92-95]}$. Lee 等 ${ }^{[63]}$ 选择以二联 BDT 单元为中心核, 三联噻吩为 $\pi$ 桥, 乙基饶丹宁单元为末端基团, 设计合 成 A-D-A 型的小分子 BDT2TR(图 3). 该分子展示出宽 的吸收光谱, 吸收边带达到 $800 \mathrm{~nm}$, 对应窄的光学带 隙, 为 $1.55 \mathrm{eV}$. 小分子给体 BDT2TR 在 $450 \sim 650 \mathrm{~nm}$ 区 间有较强的吸收, 而高分子受体 N2200 的两个吸收主峰 分别在 $350 \sim 420 \mathrm{~nm}$ 和 $620 \sim 780 \mathrm{~nm}$ 区间, 因而两者能 实现吸收光谱互补, 实现对太阳光的充分利用. 将小分 子 BDT2TR 作为给体与 N2200 共混, 制备的器件 PCE 可达 $4.43 \%$. 值得注意的是, 该体系的活性层在 $150{ }^{\circ} \mathrm{C}$ 下热处理 $15 \mathrm{~h}$ 后, 仍能维持原性能的 $80 \%$; 器件在弯折 半径为 $80 \mathrm{~mm}$ 条件下经历 100 次重复弯折, 其活性层形
貌和光伏性能基本不受影响. 这些结果说明了该体系具 有良好的形貌热稳定性和机械稳定性, 也证明了小分子 给体/高分子受体体系在稳定性方面的潜力.

\section{2 基于氭基高分子受体的小分子给体/高分子受体型 有机太阳能电池}

氧基取代基具有强缺电子性质, 在 $\pi$-共轭体系中能 够有效降低能级, 因此被广泛应用于 $\mathrm{n}$ 型半导体材料的 设计中 ${ }^{[96-99]}$. 目前高效的稠环电子受体几乎都含氭基官 能团, 有研究表明氧基除了能够大幅降低 $\pi$ 体系的能级 外, 在促进激子解离等方面具有重要作用. 直至目前, 基于含氰基的稠环电子受体仍在不断突破有机太阳能 电池的效率记录, 展示出巨大的发展潜能. 鉴于此, 李 永舫等 [57]于 2017 年提出 “小分子受体高分子化” 的策 略来构筑高分子受体材料. 第一个基于此策略开发的高 分子受体材料是 PZ1(图 5), 该高分子是以稠环小分子 受体 IDIC-C16 为共聚单元与单噻吩片段共聚得到. 其 中 IDIC-C16 是与 IDIC 具有相同分子骨架，仅烷基链得 到延长的稠环电子受体, 在 PZ1 中以 IDIC-C16 为共聚 单元的目的是为了提高高分子的溶解性, 满足材料溶液 加工的要求. 高分子 PZ1 具有较低的 HOMO/LUMO 能 级, 满足其作为受体材料的要求. 重要的是, PZ1 展示出 强且宽的吸收光谱, 光学带隙仅为 $1.55 \mathrm{eV}$, 其吸收系数 高达 $1.3 \times 10^{5} \mathrm{~cm}^{-1}$, 明显高于高分子 N2200 $\left(0.3 \times 10^{5}\right.$ $\mathrm{cm}^{-1}$ ), 表明了其在光吸收方面的优势. 该高分子作为 受体材料可用于高效有机太阳能电池中, 例如, 将其与 经典高分子给体 PBDB-T 共混制备全高分子有机太阳能 电池，可以实现超过 $9 \%$ 的器件性能，该性能是当时报 道的全高分子有机太阳能电池体系的最高值. 由于 PZ1 具有宽的吸收和窄的带隙, 基于 PBDB-T:PZ1 体系器件 的外量子效率 $(\mathrm{EQE})$ 光谱展示出宽的响应范围, 从 300 $\mathrm{nm}$ 至 $800 \mathrm{~nm}$. 而且, 该活性层具有高且平衡的空穴/电 子迁移率, 特别是电子迁移率, 经过优化可达 $7.02 \times$ $10^{-4} \mathrm{~cm}^{2} \cdot \mathrm{V}^{-1} \cdot \mathrm{s}^{-1}$. 此外, 当 PZ1 与高分子给体 PM6 共 混, 更是可以实现 $11.2 \%$ 的器件性能. 这些结果证明含 氧基的高分子受体在全高分子有机太阳能电池中具有 极大的发展潜力, 同时也促使其被用于小分子给体/高 分子受体型有机太阳能电池.

2018 年, 李永舫等 ${ }^{[100]}$ 将高分子 PZ1 作为受体, 并 选择两个不同末端基团的 A-D-A 型小分子, SM1 和 DR3TBDTT(图 5), 分别作为给体材料, 构筑小分子给 体/高分子受体型有机太阳能电池. 相比含氰基乙酸酯 端基的 SM1, 含乙基饶丹宁端基的 DR3TBDTT 具有更 低的 LUMO 能级, 红移的吸收光谱和相对弱的聚集性 质. 作者通过 2D-GIWAXS 探究给受体共混的相分离形 貌(图 5), 当 PZ1 分别与两个小分子共混后, 在共混薄膜 中仅出现高分子 PZ1 的衍射信号, 说明在成膜过程中, PZ1 主导了相分离形貌，而小分子给体无规分布在薄膜 中. 受限于低的电荷传输性质, 两组器件都表现出低的 
能量转换效率. 在 SM1:PZ1 体系中, 通过溶剂添加剂 $N-$ 甲基吡咯烷酮的使用，大幅促进小分子 SM1 的结晶，同 时高分子 PZ1 的结晶也得到提高, 从而改善了薄膜的电 荷传输性质, 减少了复合的发生, 将器件性能从 $0.36 \%$ 提升至 3.97\%. 在 DR3TBDTT:PZ1 体系中, 则是选择 $\mathrm{CN}$ 作为溶剂添加剂来提高共混薄膜中给受体的结晶性, 从而改善共混薄膜的电荷传输, 最终将器件性能从 0.24\%提升至 5.86\%. 相比 SM1:PZ1 体系, DR3TBDTT: PZ1 体系展示出更高的性能, 原因是基于聚集能力更弱 的 DR3TBDTT, 活性层薄膜的相分离尺寸更小. 这些结 果说明基于氰基的高分子受体可以在小分子给体/高分 子受体体系中实现高性能, 并且在合适的给受体匹配 下, 基于氭基的高分子受体材料, 在器件性能方面有很 大的提升空间.

除了 PZ1 外, 目前基于 “小分子受体高分子化” 的 策略开发出一些具有优异性能的氰基高分子受体材料. 例如, 将 IDIC-C16 共聚单元与 BDT 单元共聚的高分子 受体 PFBDT-IDTIC, 因强的太阳光吸收能力和高的电 子迁移率，与 PM6 共混可以实现 $10.3 \%$ 的性能 ${ }^{[59]}$; 通过 与 ITIC 相同的骨架结构作为共聚单元与单噻吩共聚的 高分子 PN1 和 PT-IDTTIC 同样具有优异的吸收性质和 传输性能, 与 PM6 共混分别可以实现 $10.5 \%$ 和 $12.1 \%$ 的 性能 ${ }^{[60-61]}$. 基于稠环小分子电子受体 Y6 的骨架与其他 单元共聚同样可以开发出高性能的高分子受体材料, 如 将 Y6 单元骨架与单噻吩共聚的高分子 PJ1, 与 PBDB-T

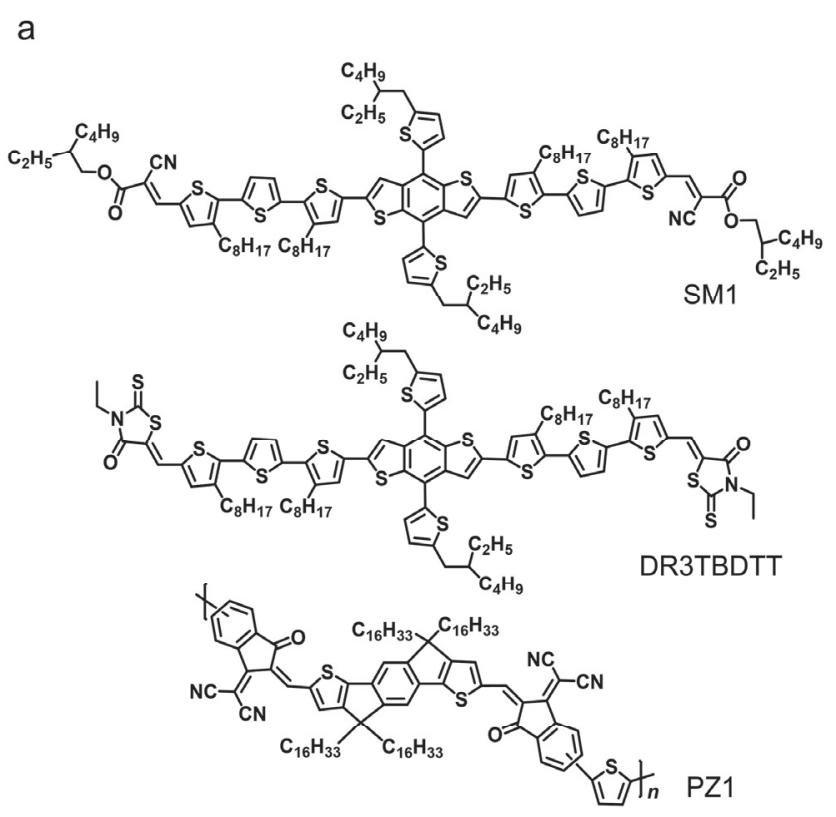

共混可以实现 $14.4 \%$ 的性能，同时该体系具有较好的形 貌热稳定性, 且在厚膜大面积器件方面展现出优异的性 能 ${ }^{[17]}$. 以上基于 “小分子受体高分子化” 的策略开发出 的氰基类高分子受体材料有力地推动了全高分子有机 太阳能电池体系的发展，极大地提升了全高分子体系的 器件性能. 我们相信将此类具有优异性能的氧基类高分 子受体材料应用于小分子给体/高分子受体体系, 将是 进一步提升该体系器件性能的有效途径.

\section{3 基于 $\mathrm{B} \leftarrow \mathrm{N}$ 类高分子受体的小分子给体/高分子受 体型有机太阳能电池}

\subsection{1 含 $\mathrm{B} \leftarrow \mathrm{N}$ 配位键的高分子受体}

有别于采用酰亚胺等缺电子单元设计高分子受体 材料的思路, 在 2015 年, 刘俊等 ${ }^{[101-102]}$ 利用 $\mathrm{B} \leftarrow \mathrm{N}$ 降低 $\pi$-共轭体系的 LUMO 能级的原理提出通过 $\mathrm{B} \leftarrow \mathrm{N}$ 设计高 分子受体的策略. 基于该策略开发的 $\mathrm{B} \leftarrow \mathrm{N}$ 高分子受体 材料具有可调的能级结构、吸收光谱和电子迁移 率 ${ }^{[103-114]}$, 制备的全高分子太阳能电池器件在太阳光照 下和室内弱光下分别实现了超过 $10 \%$ 和 $27 \%$ 的 $\mathrm{PCE}^{[115-116]}$. 而这类含 $\mathrm{B} \leftarrow \mathrm{N}$ 的高效高分子受体材料也被 用于小分子给体/高分子受体体系.

在前面关于小分子给体/高分子受体体系的介绍中, 可以发现由于大多小分子给体的结晶性较强, 与高分子 受体共混的活性层相分离形貌较差, 影响激子的扩散、 解离和电荷传输, 导致器件性能较低. 因此, 对于小分

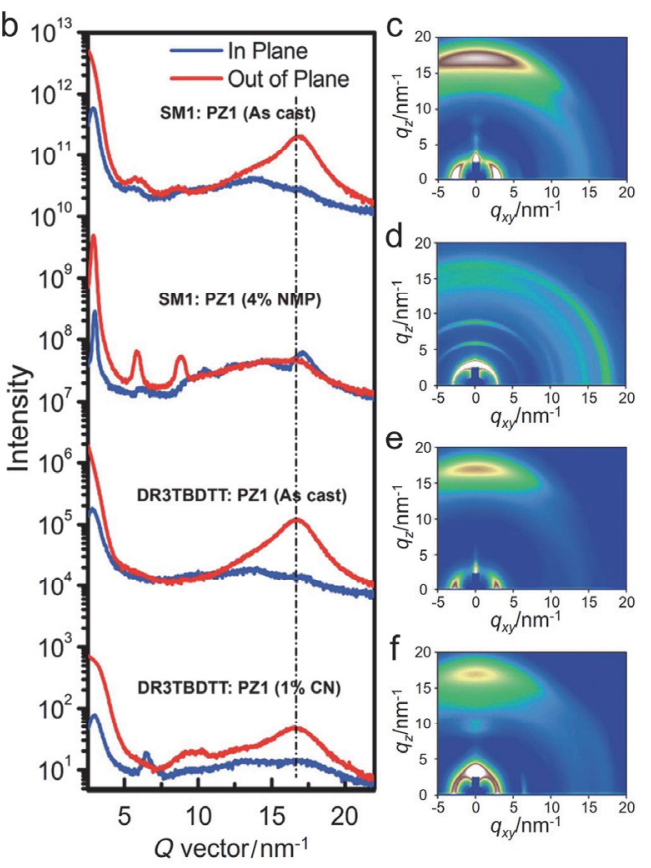

图 5 (a)小分子给体 SM1 和 DR3TBDTT 和氧基高分子受体 PZ1 的化学结构; (b) SM1:PZ1 和 DR3TBDTT:PZ1 在不同条件下的共混薄膜的 2D-GIWAXS 谱图在面内和面外方向对应的一维切线; SM1:PZ1 共混薄膜在 as-cast (c)和加入 4\% NMP (d) 条件下的 2D-GIWAXS 谱图; DR3TBDTT:PZ1 共混薄膜在 as-cast (e)和加入 $1 \% \mathrm{CN}$ (f)条件下的 2D-GIWAXS 谱图 ${ }^{[100]}$. 版权 2018, 英国皇家化学学会.

Figure 5 (a) Chemical structures of small molecule donors SM1 and DR3TBDTT and cyano-functionalized polymer acceptor PZ1; (b) 1D linecuts of 2D-GIWAXS images of SM1:PZ1 and DR3TBDTT:PZ1 blend films at different conditions; 2D-GIWAXS images of SM1:PZ1 blend film as cast (c) and with $4 \%$ NMP (d); 2D-GIWAXS images of DR3TBDTT:PZ1 blend film as cast (e) and with $1 \%$ CN (f) ${ }^{[100]}$. Copyright 2018 , The Royal Society of Chemistry. 
子给体/高分子受体型有机太阳能电池, 通过合适的手 段调控共混的相分离形貌是提升器件性能的关键. 为 此, 刘俊等[64-66,117-120]基于含 $\mathrm{B} \leftarrow \mathrm{N}$ 的高分子受体材料, 针对小分子给体/高分子受体体系共混的相分离尺寸大 的问题, 开展了一系列工作.

\subsection{2 通过添加剂调控小分子给体/含 $\mathrm{B} \leftarrow \mathrm{N}$ 配位键的} 高分子受体共混相分离形貌

高分子受体 P-BNBP-T(图 6) 是由含 $\mathrm{B} \leftarrow \mathrm{N}$ 的缺电子 构筑单元 BNBP 和单噻吩交替共聚得到. P-BNBP-T 具

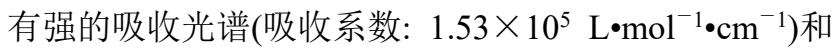
较高的电子迁移率 $\left(6.9 \times 10^{-5} \mathrm{~cm}^{2} \cdot \mathrm{V}^{-1} \cdot \mathrm{s}^{-1}\right)$. 该高分子的 LUMO/HOMO 能级分别为 $-3.50 \mathrm{eV} /-5.77 \mathrm{eV}$, 该能级 使其可以与经典的小分子给体 $p$-DTS(FBTTh - $_{2}$ (图 3)匹 配, 为此将两者共混制备了有机太阳能电池器件 [117]. 针对 $p$-DTS(FBTTh $)_{2}$ :P-BNBP-T 的活性层, 作者系统研 究了热退火和溶剂添加剂 DIO 对其相分离形貌和器件 性能的影响. 结果发现, 热退火可以有效促进小分子的 聚集, 增加其结晶性, 从而改善薄膜的电荷传输性质; 但经过热退火处理后形成的是连续性较差的短粗聚集 体, 薄膜的相分离尺寸仍然较大. 因此, 基于热退火处 理的电池器件性能仅从 $1.00 \%$ 提升至 $2.75 \%$. 作为对比, 通过在共混溶液中加入少量溶剂添加剂 DIO, 利用小分 子给体 $p$-DTS(FBTTh $\left.{ }_{2}\right)_{2}$ 在 DIO 中溶解性差的特点, 增 加 $p$-DTS $\left(\mathrm{FBTTh}_{2}\right)_{2}$ 在溶液中的成核密度, 使其形成小 尺寸的聚集体, 从而降低相分离尺寸, 可以将器件性能 提升至 3.50\%. 另外, 由于 P-BNBP-T 的 LUMO 能级相 对较高, 使其与 $p$-DTS(FBTTh $\left.{ }_{2}\right)_{2}$ 的 HOMO 能级之间的 差值较大, 因此该体系可以实现较大的 $V_{\mathrm{OC}}$, 达到 1.08 V. 这些结果证明含 $B \leftarrow N$ 的高分子受体材料可以应用 于小分子给体/高分子受体型有机太阳能电池.

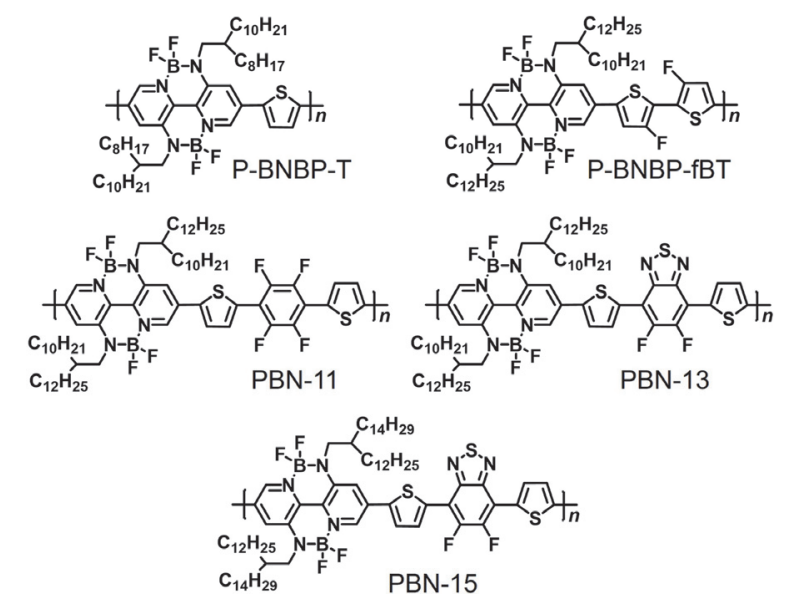

图 6 含硼氮配位键 $(B \leftarrow N)$ 的高分子受体的化学结构

Figure 6 Chemical structures of polymer acceptors containing boronnitrogen coordination bond $(\mathrm{B} \leftarrow \mathrm{N})$ unit

2.3.3 通过三元策略调控小分子给体/含 $\mathrm{B} \leftarrow \mathrm{N}$ 配位键 的高分子受体共混相分离形貌

三元共混是将三种不同的给、受体材料共混而制备
活性层的方法，该方法除了拓宽活性层的吸收、促进激 子解离外，还可以调控活性层的共混形貌，常用来发展 高效的有机太阳能电池. 在小分子给体/高分子受体体 系中, 因小分子给体的结晶尺寸大导致给受体共混的相 分离尺寸大, 为此作者采用三元共混的策略来调控共混 的相分离形貌. 作者选择两个具有相同共轭骨架而不同 烷基侧链的小分子 BTR(图 7)和 DR3TBDTT(图 5)作为 给体，选择含 $\mathrm{B} \leftarrow \mathrm{N}$ 的高分子 P-BNBP-fBT(图 6)作为受 体, 通过三元共混的方法制备有机太阳能电池器件 ${ }^{[118]}$. 相比 BTR:P-BNBP-fBT 体系和 DR3TBDTT:P-BNBPfBT 体系的二元共混, BTR:DR3TBDTT:P-BNBP-fBT 体 系的三元共混可以有效抑制小分子的结晶，降低相区尺 寸，提高激子解离的效率; 另一方面，通过三元共混的 策略可以使小分子给体的分子取向由 edge-on 转变为 face-on, 从而改善了电荷的传输. 最终, 该体系的器件 性能由二元共混的 $3.60 \%$ 或 $3.85 \%$ 提升至三元共混的 $4.85 \%$.

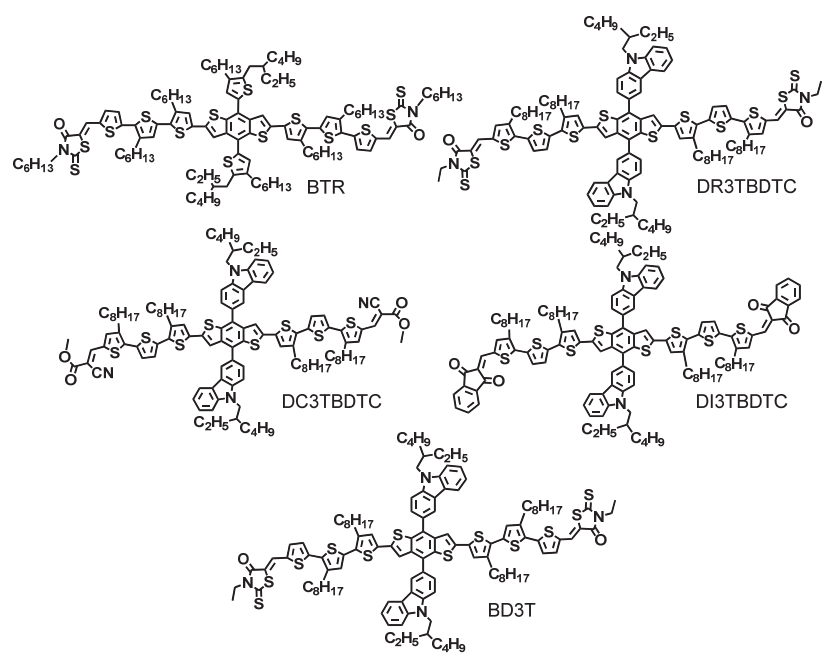

图 7 包含 $\mathrm{B} \leftarrow \mathrm{N}$ 高分子受体的小分子给体/高分子受体型有机太阳能 电池中小分子给体的化学结构

Figure 7 Chemical structures of small molecule donors for $\mathrm{M}_{\mathrm{D}} / \mathrm{P}_{\mathrm{A}}$-type OSCs with polymer acceptors containing $\mathrm{B} \leftarrow \mathrm{N}$ unit

2.3.4 通过调节小分子给体的 $\pi-\pi$ 堆积性质调控小分子 给体/含 $\mathrm{B} \leftarrow \mathrm{N}$ 配位键的高分子受体共混相分离形貌

尽管通过溶剂添加剂或三元共混的方法可以有效 调控小分子给体/高分子受体体系的共混形貌，但是该 体系器件的能量转换效率依然不高. 限制器件效率的根 源在于所用的小分子给体大多具有强聚集性和高结晶 性，与高分子受体共混后容易过度自聚集，导致大尺寸 的相分离形貌。例如 A-D-A 构型的小分子给体 DR3TBDTT，因使用具有大的刚性平面结构的 BDT 单 元为中心核, 三联噻吩为 $\pi$ 桥, 芳香结构的乙基饶丹宁 为端基, 该分子具有强的结晶性和聚集能力, 可在 2D-GIWAXS 中显示出多级衍射峰. 因富勒烯体系的形 貌易于调节, 将 DR3TBDTT 与富勒烯受体 $\mathrm{PC}_{71} \mathrm{BM}$ 共 混, 可以得到良好的相分离形貌, 实现超过 $9 \%$ 的器件 
性能. 然而当其与高分子受体共混时, 容易形成大尺寸 的相分离形貌, 影响激子解离和电荷传输, 导致性能较 低. 对此, 在小分子给体 DR3TBDTT 的分子骨架基础 上，通过将中心核 $\mathrm{BDT}$ 单元上的噻吩侧基替换为咔唑 侧基, 开发出中心核带有大体积侧基的小分子给体 DR3TBDTC(图 7) ${ }^{[64,119]}$. 理论计算结果显示在 DR3TBDTC 中, 中心核 BDT 单元与咔唑侧基之间的二 面角为 $58^{\circ}$, 说明咔唑侧基被作为位阻基团引入到分子 中, 并且由于咔唑基体积较大, 因此在固态堆积中可能 会作为大位阻抑制分子的堆积. 通过 2D-GIWAXS 测试 其固态薄膜发现, DR3TBDTC 的 $\pi-\pi$ 堆积距离 $\left(d_{\pi-\pi}\right)$ 可达 $0.388 \mathrm{~nm}$, 明显大于 DR3TBDTT $\left(d_{\pi-\pi}=0.364 \mathrm{~nm}\right)$, 说明 DR3TBDTC 的大位阻侧基减弱了分子间的 $\pi-\pi$ 相互作 用. 将小分子 DR3TBDTC 和 DR3TBDTT 分别作为给体, 含 $\mathrm{B} \leftarrow \mathrm{N}$ 的高分子 $\mathrm{PBN}-11$ (图 6)作为受体, 制备有机太 阳能电池器件. 在 DR3TBDTC:PBN-11 体系中, 由于 DR3TBDTC 的 $\pi-\pi$ 堆积能力较弱, 在成膜过程中表现出 无定形性质, 而高分子受体 PBN-11 可以形成有序聚集; 经热退火处理后, DR3TBDTC 的结晶性提升, 形成纳米 聚集体, 从而使共混薄膜形成给受体互穿网络结构(图 8). 相反, 在 DR3TBDTT:PBN-11 体系中, 由于 DR3TBDTT 的 $\pi-\pi$ 堆积能力较强, 在成膜过程中其容易 形成非连续性的大尺寸聚集体, 从而抑制 PBN-11 的有 序聚集(图 8), 最终, 得益于激子解离效率的改善和电荷 传输能力的提升, 基于含有大位阻侧基的小分子给体 DR3TBDTC 的活性层体系实现了 $8.01 \%$ 的器件性能, 明 显高于 DR3TBDTT 体系的 3.06\%(图 8). DR3TBDTC: PBN-11 体系 $8.01 \%$ 的器件性能是当时小分子给体/高分 子受体体系的最高值, 同时该结果说明通过弱 $\pi-\pi$ 堆积 能力的小分子给体与具有一定聚集能力的高分子受体 匹配, 可以达到降低共混薄膜相分离尺寸的目的. 另外, 该体系的活性层具有极好的热稳定性, 经 $180{ }^{\circ} \mathrm{C}$ 热处 理 $7 \mathrm{~d}$, 仍能维持初始性能的 $89 \%$. 通过 2D-GIWAXS 和 AFM 测试发现, 该体系经高温热处理, 活性层形貌几乎 不发生变化, 这也是其活性层热稳定性优异的原因. 通 过 DSC 测试发现，小分子给体 DR3TBDTC 具有高的熔 融温度 $\left(T_{\mathrm{m}}=253{ }^{\circ} \mathrm{C}\right)$ 和结晶温度 $\left(T_{\mathrm{c}}=223{ }^{\circ} \mathrm{C}\right)$, 而高分 子受体 $\mathrm{PBN}-11$ 在 25 到 $300{ }^{\circ} \mathrm{C}$ 之间都没有相转变, 说明 给受体材料具有高的相稳定性. 此外, DR3TBDTC 高的 结晶性可以在成膜后形成结晶的互穿网络结构, 从而有 效地抑制在热退火过程中共混薄膜里面非结晶分子的 扩散. DR3TBDTC 和 PBN-11 高的相稳定性以及 DR3TBDTC 高的结晶性决定了该体系具有优异的形貌 热稳定性.

在中心核带有大位阻的小分子给体 DR3TBDTC 的 基础上, 作者进一步研究了其末端基团对小分子给体/ 高分子受体体系的影响. 通过选择不同拉电子能力的氰 基乙酸甲酯、乙基饶丹宁和狮满二酮端基, 得到
DC3TBDTC、DR3TBDTC 和 DI3TBDTC 等三个小分子 给体(图 7) ${ }^{[120]}$. 结果发现不同拉电子能力的端基主要影 响材料的能级和吸收光谱, 随端基拉电子能力的增强, 材料的 LUMO 能级逐渐降低, 对应带隙减小, 吸收光谱 红移. 作者选择高分子 PBN-13(图 6)作为受体，与该系 列小分子给体共混, 制备有机太阳能电池器件. 通过原 子力显微镜(AFM)测试发现, 小分子给体端基的变化对 给受体共混的相分离形貌影响较小. 结果, 含乙基饶丹 宁端基的小分子 DR3TBDTC 因合适的能级和堆积性展 示出最高的器件性能.
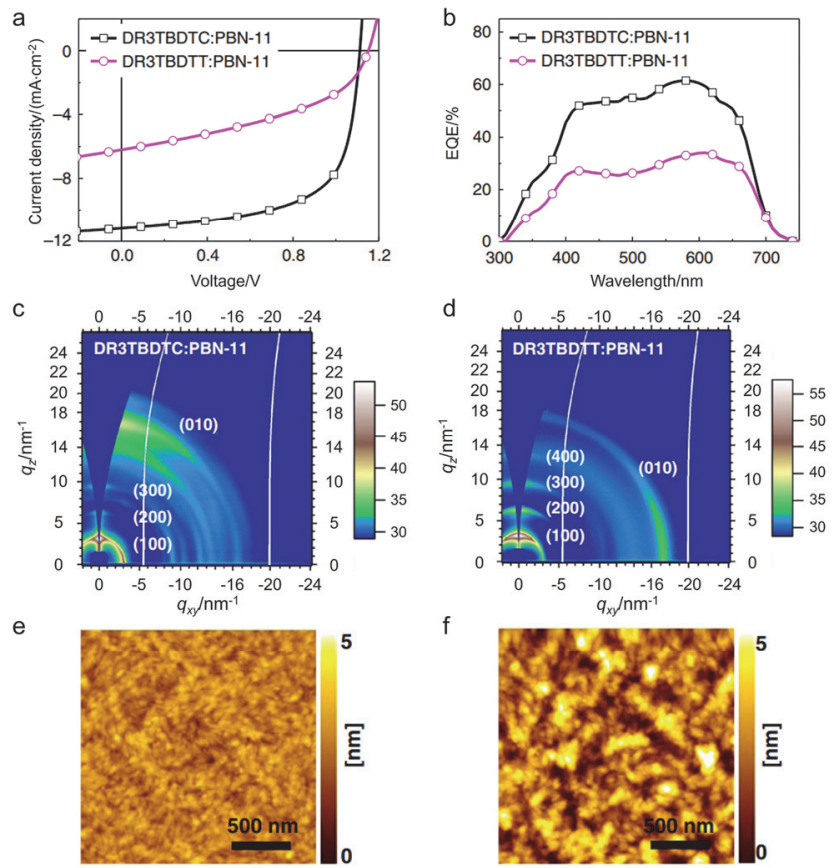

图 8 基于 DR3TBDTC:PBN-11 和 DR3TBDTT:PBN-11 体系器件的 $J-V$ 图 (a) 和 $\mathrm{EQE}$ 曲线 (b); 基于 DR3TBDTC:PBN-11 和 DR3TBDTT:PBN-11 共混薄膜的 2D-GIWAXS 谱图(c, d) 和 AFM 高度 图(e, f $)^{[64]}$

Figure 8 (a) $J-V$ plots and (b) EQE curves of the OSC devices based on DR3TBDTC:PBN-11 and DR3TBDTT:PBN-11 blend films; 2D-GIWAXS patterns (c, d) and AFM height images (e, f) of DR3TBDTC:PBN-11 and DR3TBDTT:PBN-11 blend films ${ }^{[64]}$

2.3.5 通过调控高分子受体的分子量调控小分子给体/ 含 $\mathrm{B} \leftarrow \mathrm{N}$ 配位键的高分子受体共混相分离形貌

高分子的分子量不仅影响高分子在溶液中的溶解 性和聚集性, 而且影响高分子在成膜过程中链段的扩散 速率，因此，高分子的分子量对共混薄膜的相分离形貌 和器件性能具有重要影响。作者选择小分子 DR3TBDTC 为给体, 不同分子量(18.2、66.4 和 117.3 $\left.\mathrm{kg} \cdot \mathrm{mol}^{-1}\right)$ 的高分子 P-BNBP-fBT 为受体, 制备有机太阳 能电池器件, 系统研究了高分子的分子量对小分子给 体/高分子受体型有机太阳能电池的共混形貌和器件性 能的影响 ${ }^{[65]}$. 结果发现, 低分子量的高分子受体在溶液 中的聚集能力较弱, 与 DR3TBDTC 共混成膜时, DR3TBDTC 的结晶主导相分离形貌，导致相区尺寸较 
大; 高分子量的高分子受体在溶液中具有强的聚集能 力, 与 DR3TBDTC 共混成膜时, 能够有效抑制小分子 的结晶, 从而获得小尺寸的相分离形貌. 最终, 随着高 分子受体的分子量逐渐增加, 共混活性层的相区尺寸逐 渐减小, 器件性能逐渐提升. 该结果说明通过高分子受 体的分子量可以有效调控小分子给体/高分子受体体系 共混的相分离形貌, 也为小分子给体/高分子受体体系 中高分子受体材料分子量的选择提供了方向.

2.3.6 发展高温稳定的小分子给体/高分子受体型有机 太阳能电池器件

基于小分子给体/高分子受体体系形貌热稳定性优 异的特点, 为了进一步发展高温稳定的器件, 作者开发 出具有更高相转变温度的小分子 BD3T(图 7)作为给体, 选择强聚集性质的高分子 PBN-15(图 6)作为受体构筑有 机太阳能电池器件 [66]. 在成膜过程中, 通过具有强溶液 聚集性质的高分子受体 PBN-15 抑制 BD3T 的结晶，从 而获得小尺寸的相分离形貌, 最终实现 $9.51 \%$ 的能量转 换效率. 该性能是目前小分子给体/高分子受体体系的 最高值. 更重要的是, 该体系的活性层具有优异的形貌 热稳定性, 进一步通过界面优化, 开发出可在高温下工 作的电池器件. 为了提升器件的高温耐受性, 将上述器 件中高温易扩散和团聚的无机类阳极界面层三氧化钼 $\left(\mathrm{MoO}_{3}\right)$ 替换为热稳定性更为优异的有机聚合物阳极界 面层 PEDOT:PSS (poly(3,4-ethylenedioxythiophene): poly(styrenesulfonate)). 结果基于 BD3T:PBN-15 的有机 太阳能电池器件可以在高温 $150{ }^{\circ} \mathrm{C}$ 条件下工作, 而且 在 $150{ }^{\circ} \mathrm{C}$ 条件下热处理 $72 \mathrm{~h}$, 仍能维持原性能的 84\%(图 9). 同时对比了文献中稳定性优异的高分子给 体 / 小分子受体型有机太阳能电池, 如 PTB7-Th:EH-IDTBR 体系, 结果该体系同样在 $150{ }^{\circ} \mathrm{C}$ 条 件下热处理 $72 \mathrm{~h}$, 性能出现明显降低, 仅能维持原性能 的 $62 \%$. 通过偏光显微镜观察 BD3T:PBN-15 体系和 PTB7-Th:EH-IDTBR 体系在 $150{ }^{\circ} \mathrm{C}$ 条件下热处理不同 时间的薄膜形貌, 可以发现前者在 $150{ }^{\circ} \mathrm{C}$ 下热处理几 乎不发生改变, 而后者随热处理时间的延长, 出现越来 越多的球晶, 且体积逐渐增大, 而这些球晶可能来自于 小分子受体 EH-IDTBR 的结晶. PTB7-Th:EH-IDTBR 在 热处理过程中形貌的不稳定可能是其性能降低的主要 原因。作为对比, 小分子给体/高分子受体体系 BD3T:PBN-15 则具有优异的形貌热稳定性. 该工作证 明了基于小分子给体/高分子受体体系, 可以开发出高 效的高温耐受型有机太阳能电池器件.

在以上基于含 $\mathrm{B} \leftarrow \mathrm{N}$ 的高分子受体的小分子给体/ 高分子受体型有机太阳能电池中, 刘俊等针对给受体共 混的活性层相分离尺寸大的问题, 通过溶剂添加剂、三 元共混以及给受体材料的匹配等方法, 有效调控了共混 的相分离形貌. 不仅将小分子给体/高分子受体型有机 太阳能电池的能量转换效率提升至 $9.51 \%$, 而且开发出
可在高温 $150{ }^{\circ} \mathrm{C}$ 下工作的电池器件.
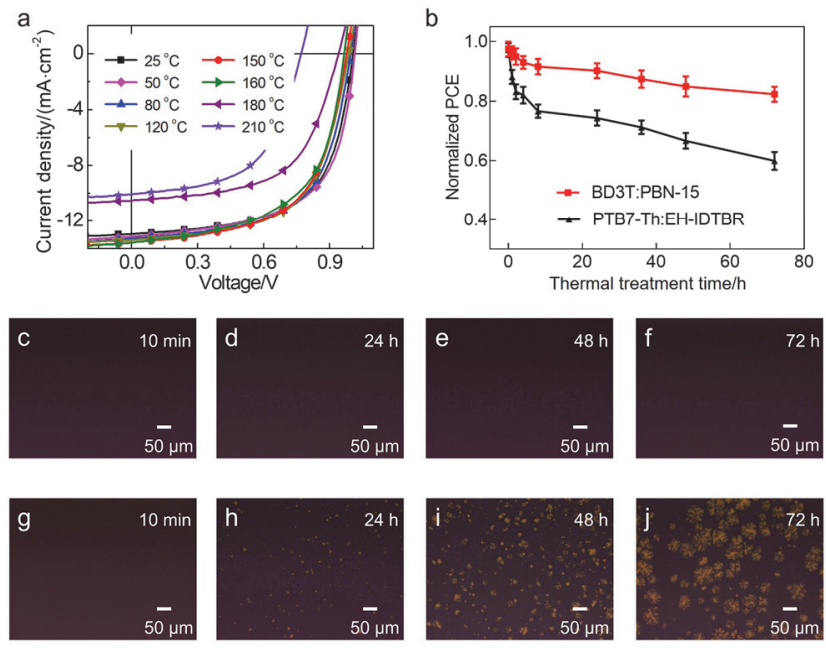

图 9 (a)基于 BD3T:PBN-15 体系器件在不同测试温度下的 $J-V$ 图; (b) 基于 BD3T:PBN-15 和 PTB7-Th:EH-IDTBR 体系器件在 $150{ }^{\circ} \mathrm{C}$ 下热处 理不同时间的器件性能; 基于 BD3T:PBN-15 $(\mathrm{c} \sim \mathrm{f})$ 和 PTB7-Th: EH-IDTBR $(g \sim j)$ 活性层在 $150{ }^{\circ} \mathrm{C}$ 下热处理不同时间的偏光显微镜 图 ${ }^{[66]}$. 版权 2020, 英国皇家化学学会.

Figure 9 (a) $J-V$ plots of the BD3T:PBN-15 device at different test temperatures; (b) the normalized PCE for the OSC devices based on BD3T:PBN-15 and PTB7-Th:EH-IDTBR blends with thermal treatment of the devices at $150{ }^{\circ} \mathrm{C}$ for different time periods; the polarized optical microscopy images of the $(\mathrm{c} \sim \mathrm{f}) \mathrm{BD} 3 \mathrm{~T}: \mathrm{PBN}-15$ active layer and $(\mathrm{g} \sim \mathrm{j})$ PTB7-Th:EH-IDTBR active layer after thermal treatment at $150{ }^{\circ} \mathrm{C}$ for different time periods ${ }^{[66]}$. Copyright 2020 , The Royal Society of Chemistry.

\section{3 结论与展望}

在有机太阳能电池中，以小分子给体和高分子受体 的共混物为活性层的小分子给体/高分子受体体系是非 富勒烯类有机太阳能电池的重要组成部分, 具有形貌热 稳定性优异的特点. 本综述总结了小分子给体/高分子 受体型有机太阳能电池的相关研究进展，分别介绍了以 酰亚胺基、氰基和含 $\mathrm{B} \leftarrow \mathrm{N}$ 的高分子作为受体的小分子 给体/高分子受体体系的发展状况. 从活性层中给受体 材料的分子设计、相分离形貌调控角度优化器件性能, 实现了小分子给体/高分子受体型太阳能电池的能量转 换效率从 2014 年的 $0.29 \%$ 到目前的 $9.51 \%$ 的提升. 更加 值得关注的是，基于相稳定性优异的小分子给体和高分 子受体材料体系, 开发出的小分子给体/高分子受体型 太阳能电池的活性层通常具有优异的热稳定性, 实现了 可在 $150{ }^{\circ} \mathrm{C}$ 下工作的耐高温器件.

虽然目前小分子给体/高分子受体型有机太阳能电 池取得了很大的研究进展, 但是相比其他类型的太阳能 电池体系, 如具有稠环电子受体的高分子给体/小分子 受体体系，小分子给体/高分子受体体系的研究依然较 少, 在器件性能方面仍有一定的差距. 高效的有机太阳 能电池通常要求活性层中给受体材料具有匹配的能级、 宽的吸收光谱、高且平衡的电荷迁移率以及合适的共混 相分离形貌，而当前已报道的小分子给体/高分子受体 
体系仍存在一些问题. 例如目前基于 $\mathrm{B} \leftarrow \mathrm{N}$ 高分子受体 的 BD3T:PBN-15 体系, 虽然实现了超过 9\%的能量转换 效率，但其活性层的光谱响应范围仅从 $300 \mathrm{~nm}$ 至 700 $\mathrm{nm}$, 窄的吸收光谱限制了其对太阳光的有效利用, 造成 能量损失, 限制器件性能的进一步提升. 因此对于该体 系, 选择窄带隙的高分子受体与给体进行匹配是提升器 件性能的一个有效途径. 另外, 以含氭基的高分子为受 体的小分子给体/高分子受体体系也是一类极具潜力的 材料体系. 根据文献报道, 基于这种稠环小分子电子受 体的聚合策略发展的高分子受体在能级结构、吸收光谱 和电子迁移率方面均满足高效材料体系的要求. 但目前 基于此类高分子受体报道的小分子给体/高分子受体体 系太少, 仅有 SM1:PZ1 和 DR3TBDTT:PZ1 体系. 因此, 可以尝试将更多此类高分子受体材料应用于小分子给 体/高分子受体体系, 从而拓展材料体系, 提升器件性 能.

鉴于目前小分子给体/高分子受体型有机太阳能电 池在器件效率方面和稳定性方面所取得的研究进展, 我 们认为, 通过活性层给受体材料的开发, 相分离形貌的 调控以及界面优化等, 该类型的太阳能电池有很大的效 率提升空间和实际应用潜力.

\section{作者简介}

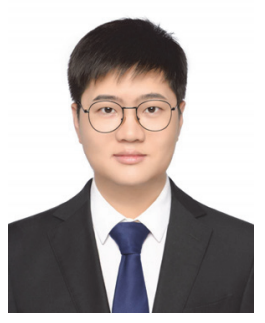

苗俊辉, 2015 年本科毕业于郑州大学, 2020 年在中国科学 院长春应用化学研究所获得博士学位, 导师是刘俊研究员. 目前在长春应用化学研究所刘俊研究员课题组开展研究工作, 研究方向是有机太阳能电池的活性层材料开发与性能研究.

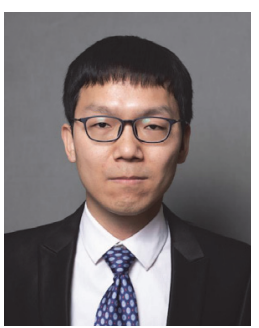

丁自成, 男, 副研究员. 研究方向为有机太阳能电池, 包 括石, 墨烯量子点电极界面材料开发与应用、小分子给体/高分 子受体型有机太阳能电池和全高分子太阳能电池活性层形貌 调控研究, 迄今发表学术论文 30 余篇, 主持国家自然科学基 金 2 项.

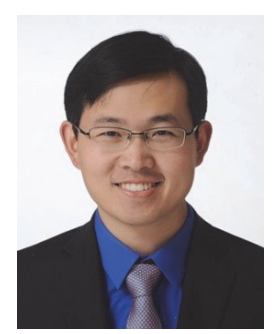

刘俊, 男, 中国科学院长春应用化学研究所研究员. 2001 年本科毕业于武汉大学, 2007 年在长春应用化学研究所获得 博士学位, 2007 2012 年在德国维尔茨堡大学、美国加州大学 洛杉矶分校、美国凯斯西储大学做博士后研究. 2013 年加入长 春应用化学研究所, 开展独立研究. 2016 年获得国家杰出青年 科学基金. 研究领域为光电功能高分子和全高分子太阳能电 池. 代表性成果为硼氮配位键高分子半导体和小分子半导体.

\section{References}

[1] Yu, G.; Gao, J.; Hummelen, J. C.; Wudl, F.; Heeger, A. J. Science 1995, 270, 1789.

[2] Tong, Y.; Xiao, Z.; Du, X.; Zuo, C.; Li, Y.; Lv, M.; Yuan, Y.; Yi, C.; Hao, F.; Hua, Y.; Lei, T.; Lin, Q.; Sun, K.; Zhao, D.; Duan, C.; Shao, X.; Li, W.; Yip, H.-L.; Xiao, Z.; Zhang, B.; Bian, Q.; Cheng, Y.; Liu, S.; Cheng, M.; Jin, Z.; Yang, S.; Ding, L. Sci. China: Chem. 2020, $63,758$.

[3] Wang, W.; Wang, J.; Zheng, Z.; Hou, J. Acta Chim. Sinica 2020, 78, 382 (in Chinese). (王文璇, 王建邱, 郑众, 侯剑辉, 化学学报, 2020, 78, 382.)

[4] Liu, H.; Zhang, X.; Cheng, J.; Ye, D.; Chen, L.; Wen, H.; Liu, S Chin. J. Org. Chem. 2020, 40, 831 (in Chinese). (刘慧, 张小凤, 程 敬招, 叶东鼎, 陈龙, 温和瑞, 刘诗咏, 有机化学, 2020, 40, 831.)

[5] Tang, C. W. Appl. Phys. Lett. 1986, 48, 183.

[6] Heeger, A. J. Chem. Soc. Rev. 2010, 39, 2354.

[7] Wang, G.; Adil, M. A.; Zhang, J.; Wei, Z. Adv. Mater. 2019, 31, 1805089.

[8] Duan, L.; Uddin, A. Adv. Sci. 2020, 7, 1903259.

[9] Cheng, P.; Zhan, X. Chem. Soc. Rev. 2016, 45, 2544.

[10] Wan, J.; Xu, X.; Zhang, G.; Li, Y.; Feng, K.; Peng, Q. Energy Environ. Sci. 2017, 10, 1739.

[11] Deng, D.; Zhang, Y.; Zhang, J.; Wang, Z.; Zhu, L.; Fang, J.; Xia, B.; Wang, Z.; Lu, K.; Ma, W.; Wei, Z. Nat. Commun. 2016, 7, 13740.

[12] Zhao, J.; Li, Y.; Yang, G.; Jiang, K.; Lin, H.; Ade, H.; Ma, W.; Yan, H. Nat. Energy 2016, 1, 15027.

[13] Zhang, G.; Zhao, J.; Chow, P. C. Y.; Jiang, K.; Zhang, J.; Zhu, Z.; Zhang, J.; Huang, F.; Yan, H. Chem. Rev. 2018, 118, 3447.

[14] Liu, Q.; Jiang, Y.; Jin, K.; Qin, J.; Xu, J.; Li, W.; Xiong, J.; Liu, J.; Xiao, Z.; Sun, K.; Yang, S.; Zhang, X.; Ding, L. Sci. Bull. 2020, 65, 272.

[15] Cui, Y.; Yao, H.; Zhang, J.; Xian, K.; Zhang, T.; Hong, L.; Wang, Y.; Xu, Y.; Ma, K.; An, C.; He, C.; Wei, Z.; Gao, F.; Hou, J. Adv. Mater. 2020, 32, 1908205.

[16] Wu, H.; Yue, Q.; Zhou, Z.; Chen, S.; Zhang, D.; Xu, S.; Zhou, H.; Yang, C.; Fan, H.; Zhu, X. J. Mater. Chem. A 2019, 7, 15944.

[17] Jia, T.; Zhang, J.; Zhong, W.; Liang, Y.; Zhang, K.; Dong, S.; Ying, L.; Liu, F.; Wang, X.; Huang, F.; Cao, Y. Nano Energy 2020, 72, 104718.

[18] Wang, L.; Bai, S.; Li, D.; Zhou, H. Chin. J. Org. Chem. 2020, 40, 748 (in Chinese). (王丽辉, 白锁柱, 李东勇, 周宏, 有机化学, 2020, 40, 748.)

[19] He, Y.; Li, Y. Phys. Chem. Chem. Phys. 2011, 13, 1970.

[20] Tajima, K.; Suzuki, Y.; Hashimoto, K. J. Phys. Chem. C 2008, 112, 8507.

[21] Kim, Y.; Cook, S.; Tuladhar, S. M.; Choulis, S. A.; Nelson, J.; Durrant, J. R.; Bradley, D. D. C.; Giles, M.; McCulloch, I.; Ha, C.-S.; Ree, M. Nat. Mater 2006, 5, 197.

[22] Liao, S.-H.; Jhuo, H.-J.; Cheng, Y.-S.; Chen, S.-A. Adv. Mater. 2013 25,4766 .

[23] Liu, Y.; Zhao, J.; Li, Z.; Mu, C.; Ma, W.; Hu, H.; Jiang, K.; Lin, H.; Ade, H.; Yan, H. Nat. Commun. 2014, 5, 5293.

[24] Nielsen, C. B.; Holliday, S.; Chen, H.-Y.; Cryer, S. J.; McCulloch, I. 
Acc. Chem. Res. 2015, 48, 2803.

[25] Zhao, J.; Yao, C.; Ali, M. U.; Miao, J.; Meng, H. Mater. Chem. Front. 2020, 4, 3487.

[26] Wan, X.; Li, C.; Zhang, M.; Chen, Y. Chem. Soc. Rev. 2020, 49, 2828.

[27] Liu, L.; Kan, Y.; Gao, K.; Wang, J.; Zhao, M.; Chen, H.; Zhao, C.; Jiu, T.; Jen, A.-K.-Y.; Li, Y. Adv. Mater. 2020, 32, 1907604.

[28] Lin, Y.; Adilbekova, B.; Firdaus, Y.; Yengel, E.; Faber, H.; Sajjad, M.; Zheng, X.; Yarali, E.; Seitkhan, A.; Bakr, O. M.; El-Labban, A.; Schwingenschlögl, U.; Tung, V.; McCulloch, I.; Laquai, F.; Anthopoulos, T. D. Adv. Mater. 2019, 31, 1902965.

[29] Cui, Y.; Yao, H.; Hong, L.; Zhang, T.; Tang, Y.; Lin, B.; Xian, K.; Gao, B.; An, C.; Bi, P.; Ma, W.; Hou, J. Natl. Sci. Rev. 2019, 7, 1239.

[30] Meng, L.; Zhang, Y.; Wan, X.; Li, C.; Zhang, X.; Wang, Y.; Ke, X.; Xiao, Z.; Ding, L.; Xia, R.; Yip, H.-L.; Cao, Y.; Chen, Y. Science 2018, 361, 1094

[31] Zhan, L.; Li, S.; Lau, T.-K.; Cui, Y.; Lu, X.; Shi, M.; Li, C.-Z.; Li, H.; Hou, J.; Chen, H. Energy Environ. Sci. 2020, 13, 635.

[32] Wang, T.; Sun, R.; Shi, M.; Pan, F.; Hu, Z.; Huang, F.; Li, Y.; Min, J. Adv. Energy Mater. 2020, 10, 2000590.

[33] Luo, Z.; Ma, R.; Liu, T.; Yu, J.; Xiao, Y.; Sun, R.; Xie, G.; Yuan, J.; Chen, Y.; Chen, K.; Chai, G.; Sun, H.; Min, J.; Zhang, J.; Zou, Y.; Yang, C.; Lu, X.; Gao, F.; Yan, H. Joule 2020, 4, 1236.

[34] Ma, R.; Liu, T.; Luo, Z.; Guo, Q.; Xiao, Y.; Chen, Y.; Li, X.; Luo, S.; Lu, X.; Zhang, M.; Li, Y.; Yan, H. Sci. China: Chem. 2020, 63, 325.

[35] Li, S.; Zhan, L.; Jin, Y.; Zhou, G.; Lau, T.-K.; Qin, R.; Shi, M.; Li, C.-Z.; Zhu, H.; Lu, X.; Zhang, F.; Chen, H. Adv. Mater. 2020, 32, 2001160.

[36] Lin, Y.; Wang, J.; Zhang, Z.-G.; Bai, H.; Li, Y.; Zhu, D.; Zhan, X. Adv. Mater. 2015, 27, 1170.

[37] Lin, Y.; He, Q.; Zhao, F.; Huo, L.; Mai, J.; Lu, X.; Su, C.-J.; Li, T.; Wang, J.; Zhu, J.; Sun, Y.; Wang, C.; Zhan, X. J. Am. Chem. Soc. 2016, 138, 2973.

[38] Lin, Y.; Zhao, F.; Wu, Y.; Chen, K.; Xia, Y.; Li, G.; Prasad, S. K. K.; Zhu, J.; Huo, L.; Bin, H.; Zhang, Z.-G.; Guo, X.; Zhang, M.; Sun, Y.; Gao, F.; Wei, Z.; Ma, W.; Wang, C.; Hodgkiss, J.; Bo, Z.; Inganäs, O.; Li, Y.; Zhan, X. Adv. Mater. 2017, 29, 1604155.

[39] Yue, Q.; Liu, W.; Zhu, X. J. Am. Chem. Soc. 2020, 142, 11613.

[40] Lin, Y.; Zhao, F.; He, Q.; Huo, L.; Wu, Y.; Parker, T. C.; Ma, W.; Sun, Y.; Wang, C.; Zhu, D.; Heeger, A. J.; Marder, S. R.; Zhan, X. J. Am. Chem. Soc. 2016, 138, 4955 .

[41] Dai, S.; Li, T.; Wang, W.; Xiao, Y.; Lau, T.-K.; Li, Z.; Liu, K.; Lu, X.; Zhan, X. Adv. Mater. 2018, 30, 1706571.

[42] Zhao, W.; Li, S.; Yao, H.; Zhang, S.; Zhang, Y.; Yang, B.; Hou, J. J. Am. Chem. Soc. 2017, 139, 7148.

[43] Xiao, Z.; Jia, X.; Li, D.; Wang, S.; Geng, X.; Liu, F.; Chen, J.; Yang, S.; Russell, T. P.; Ding, L. Sci. Bull. 2017, 62, 1494.

[44] Zhang, Z.; Yuan, J.; Wei, Q.; Zou, Y. Front. Chem. 2018, 6, 414.

[45] Yuan, J.; Zhang, Y.; Zhou, L.; Zhang, G.; Yip, H.-L.; Lau, T.-K.; Lu, X.; Zhu, C.; Peng, H.; Johnson, P. A.; Leclerc, M.; Cao, Y.; Ulanski, J.; Li, Y.; Zou, Y. Joule 2019, 3, 1140.

[46] Yang, L.; Zhang, S.; He, C.; Zhang, J.; Yang, Y.; Zhu, J.; Cui, Y.; Zhao, W.; Zhang, H.; Zhang, Y.; Wei, Z.; Hou, J. Chem. Mater. 2018, $30,2129$.

[47] Liang, R.-Z.; Babics, M.; Savikhin, V.; Zhang, W.; Le Corre, V. M.; Lopatin, S.; Kan, Z.; Firdaus, Y.; Liu, S.; McCulloch, I.; Toney, M. F.; Beaujuge, P. M. Adv. Energy Mater. 2018, 8, 1800264.

[48] Bin, H.; Yao, J.; Yang, Y.; Angunawela, I.; Sun, C.; Gao, L.; Ye, L.; Qiu, B.; Xue, L.; Zhu, C.; Yang, C.; Zhang, Z.-G.; Ade, H.; Li, Y. Adv. Mater. 2018, 30, 1706361.

[49] Gao, K.; Jo, S. B.; Shi, X.; Nian, L.; Zhang, M.; Kan, Y.; Lin, F.; Kan, B.; Xu, B.; Rong, Q.; Shui, L.; Liu, F.; Peng, X.; Zhou, G.; Cao, Y.; Jen, A. K.-Y. Adv. Mater. 2019, 31, 1807842.

[50] Ge, J.; Xie, L.; Peng, R.; Fanady, B.; Huang, J.; Song, W.; Yan, T.; Zhang, W.; Ge, Z. Angew. Chem., Int. Ed. 2020, 59, 2808.

[51] Qiu, B.; Chen, Z.; Qin, S.; Yao, J.; Huang, W.; Meng, L.; Zhu, H.; Yang, Y.; Zhang, Z.-G.; Li, Y. Adv. Mater. 2020, 32, 1908373.

[52] Qin, J.; An, C.; Zhang, J.; Ma, K.; Yang, Y.; Zhang, T.; Li, S.; Xian, K.; Cui, Y.; Tang, Y.; Ma, W.; Yao, H.; Zhang, S.; Xu, B.; He, C.; Hou, J. Sci. China: Mater. 2020, 63, 1142.

[53] Hu, D.; Yang, Q.; Chen, H.; Wobben, F.; Le Corre, V. M.; Singh, R.; Liu, T.; Ma, R.; Tang, H.; Koster, L. J. A.; Duan, T.; Yan, H.; Kan, Z.; Xiao, Z.; Lu, S. Energy Environ. Sci. 2020, 13, 2134.

[54] Yue, Q.; Wu, H.; Zhou, Z.; Zhang, M.; Liu, F.; Zhu, X. Adv. Mater. 2019, 31, 1904283.

[55] Wang, Y.; Wang, Y.; Zhu, L.; Liu, H.; Fang, J.; Guo, X.; Liu, F.;
Tang, Z.; Zhang, M.; Li, Y. Energy Environ. Sci. 2020, 13, 1309.

[56] Tang, H.; Chen, H.; Yan, C.; Huang, J.; Fong, P. W. K.; Lv, J.; Hu, D.; Singh, R.; Kumar, M.; Xiao, Z.; Kan, Z.; Lu, S.; Li, G. Adv. Energy Mater. 2020, 10, 2001076.

[57] Zhang, Z.-G.; Yang, Y.; Yao, J.; Xue, L.; Chen, S.; Li, X.; Morrison, W.; Yang, C.; Li, Y. Angew. Chem., Int. Ed. 2017, 56, 13503.

[58] Meng, Y.; Wu, J.; Guo, X.; Su, W.; Zhu, L.; Fang, J.; Zhang, Z.-G.; Liu, F.; Zhang, M.; Russell, T. P.; Li, Y. Sci. China: Chem. 2019, 62, 845.

[59] Yao, H.; Bai, F.; Hu, H.; Arunagiri, L.; Zhang, J.; Chen, Y.; Yu, H.; Chen, S.; Liu, T.; Lai, J. Y. L.; Zou, Y.; Ade, H.; Yan, H. ACS Energy Lett. 2019, 4, 417.

[60] Wu, J.; Meng, Y.; Guo, X.; Zhu, L.; Liu, F.; Zhang, M. J. Mater Chem. A 2019, 7, 16190.

[61] Yao, H.; Ma, L.-K.; Yu, H.; Yu, J.; Chow, P. C. Y.; Xue, W.; Zou, X.; Chen, Y.; Liang, J.; Arunagiri, L.; Gao, F.; Sun, H.; Zhang, G.; Ma, W.; Yan, H. Adv. Energy Mater. 2020, 10, 2001408.

[62] Kim, Y. J.; Chung, D. S.; Park, C. E. Nano Energy 2015, 15, 343.

[63] Oh, S.; Badgujar, S.; Kim, D. H.; Lee, W.-E.; Khan, N.; Jahandar, M.; Rasool, S.; Song, C. E.; Lee, H. K.; Shin, W. S.; Lee, J.-C.; Moon, S.-J.; Lee, S. K. J. Mater. Chem. A 2017, 5, 15923.

[64] Zhang, Z.; Miao, J.; Ding, Z.; Kan, B.; Lin, B.; Wan, X.; Ma, W.; Chen, Y.; Long, X.; Dou, C.; Zhang, J.; Liu, J.; Wang, L. Nat. Commun. 2019, 10, 3271 .

[65] Zhang, Z.; Wang, T.; Ding, Z.; Miao, J.; Wang, J.; Dou, C.; Meng, B.; Liu, J.; Wang, L. Macromolecules 2019, 52, 8682.

[66] Miao, J.; Meng, B.; Ding, Z.; Liu, J.; Wang, L. J. Mater. Chem. A 2020, 8, 10983 .

[67] Yang, Y.; Lin, F.; Zhu, C.; Chen, T.; Ma, S.; Luo, Y.; Zhu, L.; Guo, X. Acta Chim. Sinica 2020, 78, 217 (in Chinese). (杨英，林飞宇， 朱从潭, 陈甜, 马书鹏, 罗媛, 朱刘, 郭学益, 化学学报, 2020, 78, 217.)

[68] Cheng, P.; Zhao, X.; Zhou, W.; Hou, J.; Li, Y.; Zhan, X. Org. Electron. 2014, 15, 2270.

[69] Zhan, X.; Tan, Z. a.; Domercq, B.; An, Z.; Zhang, X.; Barlow, S.; Li, Y.; Zhu, D.; Kippelen, B.; Marder, S. R. J. Am. Chem. Soc. 2007, 129, 7246.

[70] Li, S.; Zhang, H.; Zhao, W.; Ye, L.; Yao, H.; Yang, B.; Zhang, S.; Hou, J. Adv. Energy Mater. 2016, 6, 1501991.

[71] Guo, Y.; Li, Y.; Awartani, O.; Zhao, J.; Han, H.; Ade, H.; Zhao, D.; Yan, H. Adv. Mater. 2016, 28, 8483.

[72] Guo, Y.; Li, Y.; Awartani, O.; Han, H.; Zhao, J.; Ade, H.; Yan, H.; Zhao, D. Adv. Mater. 2017, 29, 1700309.

[73] Yan, H.; Chen, Z.; Zheng, Y.; Newman, C.; Quinn, J. R.; Dötz, F.; Kastler, M.; Facchetti, A. Nature 2009, 457, 679.

[74] Cho, H.-H.; Kim, S.; Kim, T.; Sree, V. G.; Jin, S.-H.; Kim, F. S.; Kim, B. J. Adv. Energy Mater. 2018, 8, 1701436.

[75] Deng, P.; Ho, C. H. Y.; Lu, Y.; Li, H.-W.; Tsang, S.-W.; So, S. K.; Ong, B. S. Chem. Commun. 2017, 53, 3249.

[76] You, H.; Kim, D.; Cho, H.-H.; Lee, C.; Chong, S.; Ahn, N. Y.; Seo, M.; Kim, J.; Kim, F. S.; Kim, B. J. Adv. Funct. Mater. 2018, 28, 1803613.

[77] Liu, X.; Zhang, C.; Duan, C.; Li, M.; Hu, Z.; Wang, J.; Liu, F.; Li, N.; Brabec, C. J.; Janssen, R. A. J.; Bazan, G. C.; Huang, F.; Cao, Y. J. Am. Chem. Soc. 2018, 140, 8934.

[78] Wu, Y.; Schneider, S.; Walter, C.; Chowdhury, A. H.; Bahrami, B. Wu, H.-C.; Qiao, Q.; Toney, M. F.; Bao, Z. J. Am. Chem. Soc. 2020, $142,392$.

[79] Wang, Y.; Zhao, X.; Zhan, X. J. Mater. Chem. C 2015, 3, 447.

[80] Geng, Y.; Xiao, B.; Izawa, S.; Huang, J.; Tajima, K.; Zeng, Q.; Zhou, E. J. Mater. Chem. A 2015, 3, 22325.

[81] Fan, B.; Ying, L.; Wang, Z.; He, B.; Jiang, X.-F.; Huang, F.; Cao, Y. Energy Environ. Sci. 2017, 10, 1243.

[82] Zhu, L.; Zhong, W.; Qiu, C.; Lyu, B.; Zhou, Z.; Zhang, M.; Song, J.; Xu, J.; Wang, J.; Ali, J.; Feng, W.; Shi, Z.; Gu, X.; Ying, L.; Zhang, Y.; Liu, F. Adv. Mater. 2019, 31, 1902899.

[83] Fan, B.; Ying, L.; Zhu, P.; Pan, F.; Liu, F.; Chen, J.; Huang, F.; Cao, Y. Adv. Mater. 2017, 29, 1703906.

[84] Fan, B.; Zhu, P.; Xin, J.; Li, N.; Ying, L.; Zhong, W.; Li, Z.; Ma, W.; Huang, F.; Cao, Y. Adv. Energy Mater. 2018, 8, 1703085.

[85] Li, Z.; Lin, J. D. A.; Phan, H.; Sharenko, A.; Proctor, C. M.; Zalar, P.; Chen, Z.; Facchetti, A.; Nguyen, T.-Q. Adv. Funct. Mater. 2014 24,6989

[86] Zhang, X.; Xiao, C.; Zhang, A.; Yang, F.; Dong, H.; Wang, Z.; Zhan, X.; Li, W.; Hu, W. Polym. Chem. 2015, 6, 4775.

[87] Jung, I. H.; Kim, J.-H.; Nam, S. Y.; Lee, C.; Hwang, D.-H.; Yoon, S. 
C. Macromolecules 2015, 48, 5213.

[88] Yuan, J.; Ma, W. Org. Electron. 2016, 39, 279.

[89] Tang, Z.; Liu, B.; Melianas, A.; Bergqvist, J.; Tress, W.; Bao, Q.; Qian, D.; Inganäs, O.; Zhang, F. Adv. Mater. 2015, 27, 1900.

[90] Jung, J. W.; Russell, T. P.; Jo, W. H. Chem. Mater. 2015, 27, 4865.

[91] Liu, S.-Y.; Jung, J. W.; Li, C.-Z.; Huang, J.; Zhang, J.; Chen, H.; Jen, A. K. Y. J. Mater. Chem. A 2015, 3, 22162.

[92] Liu, Y.; Wan, X.; Wang, F.; Zhou, J.; Long, G.; Tian, J.; Chen, Y. Adv. Mater. 2011, 23, 5387.

[93] Zhou, J.; Wan, X.; Liu, Y.; Zuo, Y.; Li, Z.; He, G.; Long, G.; Ni, W.; Li, C.; Su, X.; Chen, Y. J. Am. Chem. Soc. 2012, 134, 16345.

[94] Zhou, J.; Zuo, Y.; Wan, X.; Long, G.; Zhang, Q.; Ni, W.; Liu, Y.; Li, Z.; He, G.; Li, C.; Kan, B.; Li, M.; Chen, Y. J. Am. Chem. Soc. 2013, 135,8484 .

[95] Sun, K.; Xiao, Z.; Lu, S.; Zajaczkowski, W.; Pisula, W.; Hanssen, E.; White, J. M.; Williamson, R. M.; Subbiah, J.; Ouyang, J.; Holmes, A. B.; Wong, W. W. H.; Jones, D. J. Nat. Commun. 2015, 6, 6013.

[96] Pappenfus, T. M.; Chesterfield, R. J.; Frisbie, C. D.; Mann, K. R.; Casado, J.; Raff, J. D.; Miller, L. L. J. Am. Chem. Soc. 2002, 124, 4184.

[97] Casey, A.; Han, Y.; Fei, Z.; White, A. J. P.; Anthopoulos, T. D.; Heeney, M. J. Mater. Chem. C 2015, 3, 265.

[98] Shi, S.; Wang, H.; Uddin, M. A.; Yang, K.; Su, M.; Bianchi, L.; Chen, P.; Cheng, X.; Guo, H.; Zhang, S.; Woo, H. Y.; Guo, X. Chem. Mater. 2019, 31, 1808.

[99] Shi, S.; Chen, P.; Chen, Y.; Feng, K.; Liu, B.; Chen, J.; Liao, Q.; Tu, B.; Luo, J.; Su, M.; Guo, H.; Kim, M.-G.; Facchetti, A.; Guo, X. Adv. Mater. 2019, 31, 1905161.

[100] Yang, Y.; Qiu, B.; Chen, S.; Zhou, Q.; Peng, Y.; Zhang, Z.-G.; Yao, J.; Luo, Z.; Chen, X.; Xue, L.; Feng, L.; Yang, C.; Li, Y. J. Mater. Chem. A 2018, 6, 9613 .

[101] Dou, C.; Ding, Z.; Zhang, Z.; Xie, Z.; Liu, J.; Wang, L. Angew. Chem., Int. Ed. 2015, 54, 3648.

[102] Dou, C.; Long, X.; Ding, Z.; Xie, Z.; Liu, J.; Wang, L. Angew. Chem., Int. Ed. 2016, 55, 1436.
[103] Zhao, R.; Liu, J.; Wang, L. Acc. Chem. Res. 2020, 53, 1557.

[104] Zhao, R.; Dou, C.; Xie, Z.; Liu, J.; Wang, L. Angew. Chem., Int. Ed. 2016, 55, 5313

[105] Zhao, R.; Lin, B.; Feng, J.; Dou, C.; Ding, Z.; Ma, W.; Liu, J.; Wang, L. Macromolecules 2019, 52, 7081.

[106] Ding, Z.; Long, X.; Dou, C.; Liu, J.; Wang, L. Chem. Sci. 2016, 7, 6197.

[107] Long, X.; Ding, Z.; Dou, C.; Zhang, J.; Liu, J.; Wang, L. Adv. Mater. 2016, 28,6504

[108] Long, X.; Yao, J.; Cheng, F.; Dou, C.; Xia, Y. Mater. Chem. Front. 2019, 3, 70 .

[109] Long, X.; Dou, C.; Liu, J.; Wang, L. Macromolecules 2017, 50, 8521 .

[110] Miao, J.; Li, H.; Wang, T.; Han, Y.; Liu, J.; Wang, L. J. Mater. Chem A 2020, 8, 20998

[111] Zhao, R.; Dou, C.; Liu, J.; Wang, L. Chin. J. Polym. Sci. 2017, 35, 198.

[112] Dou, C.; Liu, J.; Wang, L. Sci. China: Chem. 2017, 60, 450.

[113] Long, X.; Dou, C.; Liu, J.; Wang, L. Chin. Chem. Lett. 2018, 29, 1343.

[114] Long, X.; Wang, N.; Ding, Z.; Dou, C.; Liu, J.; Wang, L. J. Mater Chem. C 2016, 4, 9961.

[115] Zhao, R.; Wang, N.; Yu, Y.; Liu, J. Chem. Mater. 2020, 32, 1308.

[116] Ding, Z.; Zhao, R.; Yu, Y.; Liu, J. J. Mater. Chem. A 2019, 7, 26533.

[117] Zhang, Z.; Ding, Z.; Long, X.; Dou, C.; Liu, J.; Wang, L. J. Mater. Chem. C 2017, 5, 6812 .

[118] Zhang, Z.; Ding, Z.; Jones, D. J.; Wong, W. W. H.; Kan, B.; Bi, Z.; Wan, X.; Ma, W.; Chen, Y.; Long, X.; Dou, C.; Liu, J.; Wang, L. Sci. China: Chem. 2018, 61, 1025.

[119] Zhang, Z.; Ding, Z.; Miao, J.; Xin, J.; Ma, W.; Dou, C.; Liu, J.; Wang, L. J. Mater. Chem. C 2019, 7, 10521.

[120] Miao, J.; Meng, B.; Liu, J.; Wang, L. Org. Mater. 2019, 01, 088.

(Cheng, B.) 